\title{
Evolução metamórfica e estrutural do Complexo Várzea do Capivarita, Cinturão Dom Feliciano, Encruzilhada do Sul, RS
}

\author{
Francisco Molina BOM ${ }^{1}$, Ruy Paulo PHILIPP ${ }^{1,2} \&$ Gustavo ZVIRTES $^{1}$ \\ 1. Programa de Pós-graduação em Geociências / Centro de Estudos em Petrologia e Geoquímica, Instituto de Geociências, Universidade \\ Federal do Rio Grande do Sul. Caixa Postal 15.001, CEP 91501-970, Porto Alegre, RS, Brasil. E-mail: francisco.bom@ufrgs.br, zvirtes@ \\ yahoo.com.br. \\ 2. Centro de Estudos em Petrologia e Geoquímica, Instituto de Geociências, Universidade Federal do Rio Grande do Sul. Caixa Postal 15.001, \\ CEP 91501-970, Porto Alegre, RS, Brasil. E-mail: ruy.philipp@ufrgs.br.
}

Recebido em 10/2013. Aceito para publicação em 08/2014.

Versão online publicada em 19/09/2014 (www.pesquisasemgeociencias.ufrgs.br)

\begin{abstract}
Resumo - 0 Complexo Várzea do Capivarita está representado por paragnaisses dispostos como megaxenólitos nos granitos da Suíte Encruzilhada do Sul e como fragmentos menores nos granitos Quitéria e Cordilheira. Essas unidades graníticas afloram no extremo norte do Batólito Pelotas, porção leste do Cinturão Dom Feliciano, próximo a Encruzilhada do Sul. O complexo é constituído por gnaisses pelíticos, com ocorrência subordinada de gnaisses calci-silicáticos, mármores, gnaisses quartzo-feldspáticos e raros quartzitos. Os gnaisses pelíticos possuem injeções de corpos tabulares de muscovita leucogranitos peraluminosos com espessuras centimétricas a métricas. Neste trabalho foram feitas análises petrográficas e microestruturais de seções delgadas representativas das litologias do complexo e a caracterização estrutural da área de estudo. A integração desses dados permitiu avaliar a migmatização dos paragnaisses e a geração das injeções leucograníticas. As condições metamórficas estabelecidas com base nas paragêneses identificadas indicam temperaturas da ordem de 850 a $1000^{\circ} \mathrm{C}$ e pressões entre 6 e $10 \mathrm{kbar}$, caracterizando um metamorfismo orogênico de fácies granulito, da série de pressão intermediária e de ultra-alta temperatura (UAT). A concordância estrutural entre o bandamento $\left(\mathrm{S}_{2)}\right.$ dos paragnaisses e a foliação ígnea $\left(\mathrm{S}_{0}\right)$ do leucogranito indica que ambas foram formadas no mesmo evento, implicando que a migmatização dos paragnaisses do Complexo Várzea do Capivarita gerou os leucogranitos peraluminosos durante o ápice do metamorfismo orogênico colisional.
\end{abstract}

Palavras-chave: Cinturão Dom Feliciano, Complexo Várzea do Capivarita, Neoproterozoico, ultra-alta temperatura, metamorfismo colisional, migmatização

\begin{abstract}
Metamorphic AND STRUCTURAl EVolution of the VÁRzeA do CAPIVARita CompleX, Dom Feliciano Belt, Encruzilhada do Sul, RS. The Várzea do Capivarita Complex is represented by paragneisses disposed as megaxenoliths in the granites of the Encruzilhada do Sul Suite and as smaller fragments in the Quitéria and Cordilheira granites. These granitic units crop out in the northernmost part of the Pelotas Batholith, eastern portion of the Dom Feliciano Belt, near Encruzilhada do Sul. The complex is constituted by pelitic gneisses with subordinate calc-silicate gneisses, marble, quartz-feldspathic gneisses and rare quartzites. The pelitic gneisses have injections of centimetric to metric wide tabular bodies of muscovite bearing peraluminous leucogranites. In this work, petrographical and microestructural analysis of representative thin sections of the lithologies and the structural characterization of the area were made. The integration of these data allowed evaluating the migmatization of the paragneisses and the generation of the leucogranitic injections. The metamorphic conditions established based on the identified paragenesis indicate temperatures of the order of 850 to $1000{ }^{\circ} \mathrm{C}$ and pressures between 6 and $10 \mathrm{kbar}$, characterizing a granulite facies orogenic metamorphism belonging to the intermediate pressure and ultra-high temperature (UHT) series. The structural concordance between the paragneiss $\left(\mathrm{S}_{2}\right)$ metamorphic foliation and the leucogranite magmatic foliation $\left(\mathrm{S}_{0}\right)$ indicates that both were formed in the same event, implying that the migmatization of the paragneisses of the Várzea do Capivarita Complex generated the peraluminous leucogranites during the apex of the collisional orogenic metamorphism. Keywords: Dom Feliciano Belt, Várzea do Capivarita Complex, Neoproterozoic, ultra-high temperature, collisional metamorphism, migmatization
\end{abstract}

\section{Introdução}

A determinação da evolução de um cinturão orogênico requer estudos integrados de mapeamento geológico associado a outras ferramentas como petrografia, geologia estrutural, estratigrafia e geocronologia. 0 caráter dinâmico da evolução resulta em mosaico de unidades muito fragmentadas, cuja restauração nem sempre é completa. A compreensão das unidades metamórficas inicia pela determinação do seu protólito por meio de estruturas e texturas reliquiares, das condições de sua formação, em termos de gradientes de pressão e temperatura, associadas a uma cronologia relativa de sua evolução estrutural, incluindo o com- 
portamento reológico das unidades.

O Escudo Sul-rio-grandense (ESRG) é composto por duas unidades geotectônicas principais, o Cráton Rio de la Plata e o Cinturão Dom Feliciano. Um fragmento significativo da primeira unidade está localizado no Terreno Taquarembó, extremo sudoeste do escudo. 0 Cinturão Dom Feliciano (CDF) ocupa a maior parte do escudo e está constituído pelos terrenos Tijucas, São Gabriel e pelo Batólito Pelotas (Fig. 1). A construção do cinturão envolveu inicialmente o fechamento de um oceano durante a Orogênese São Gabriel e, posteriormente, a colisão entre os crátons Rio de la Plata e Kalahari durante a Orogênese Dom Feliciano, ocorrida no final da evolução do Ciclo Orogênico Brasiliano (Babinski et al., 1996; Chemale Jr., 2000; Hartmann et al., 2007). As unidades do embasamento foram intensamente deformadas e metamorfisadas durante o processo colisional final, gerando a intercalação tectônica entre domínios infracrustais e supracrustais com ampla concordância estrutural. Esse fato dificulta a separação das unidades, tornando-se de suma importância o estudo detalhado e integrado das estruturas para desvendar a história dos eventos ocorridos no Ciclo Orogênico Brasiliano.

O Complexo Várzea do Capivarita (CVC) é uma unidade metassedimentar composta por gnaisses pelíticos, com ocorrência subordinada de gnaisses calci-silicáticos, mármores e quartzitos. No interior desse complexo são descritos corpos graníticos peraluminosos de formas tabulares e espessuras variáveis desde centimétricas até dezenas de metros. O CVC foi afetado por metamorfismo orogênico em condições de grau alto (UAT: ultra-alta temperatura) e ocorre como megaxenólitos e roof pendants no interior dos granitos da Suíte Encruzilhada do Sul, e subordinadamente, como pequenos xenólitos nos granitos Quitéria e Cordilheira, porção nordeste do Batólito Pelotas (Koester, 1995; Vasquez, 1997) (Fig. 2). Neste trabalho são apresentados novos dados petrográficos, estruturais e microestruturais dos gnaisses do CVC e de granitos peraluminosos associados. Esses dados permitiram estabelecer, a partir da interpretação das paragêneses metamórficas e das relações estruturais, as condições metamórficas do complexo e a sua provável vinculação como fonte do magmatismo leucocrático peraluminoso que ocorre na região.

O principal objetivo deste trabalho é apresentar as condições metamórficas, a caracterização estrutural e a evolução do complexo e dos granitos peraluminosos com base em dados petrográficos e estruturais.

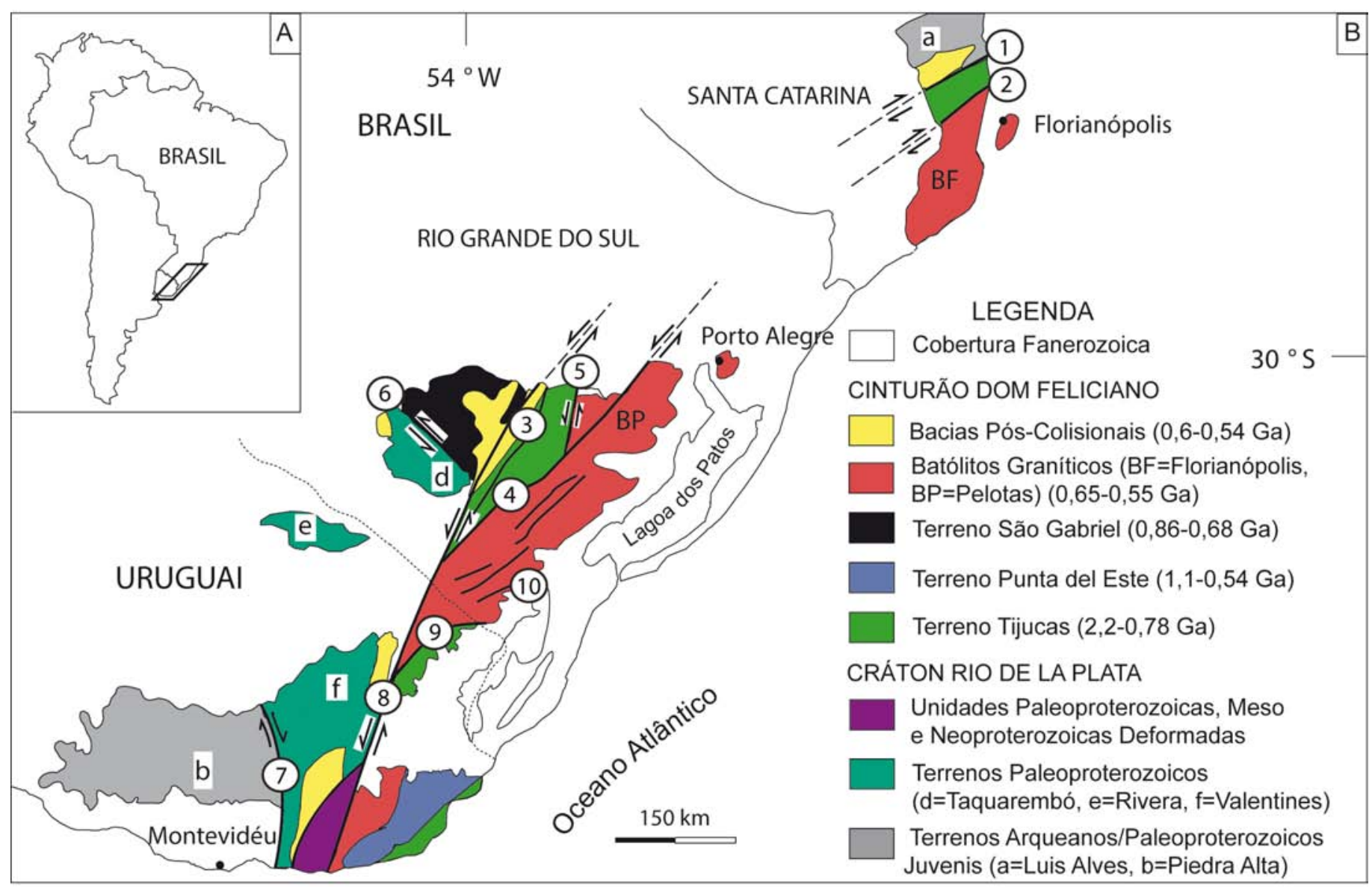

Figura 1. Mapa geral de localização e correlação das unidades geotectônicas. A) Localização da área estudada na América do Sul. B) Principais unidades geotectônicas do sul do Brasil e Uruguai. Principais zonas de cisalhamento: 1 - Itajaí-Perimbó, 2 - Major Gercino, 3 - Santana da Boa Vista, 4 - Dorsal de Canguçu, 5 - Passo do Marinheiro, 6 - Ibaré, 7 - Sarandi del Yí, 8 - Sierra Ballena, 9 - Cerro Amaro, 10 - Arroio Grande. Modificado de Philipp et al. (2013) e Oyhantçabal et al. (2009). 


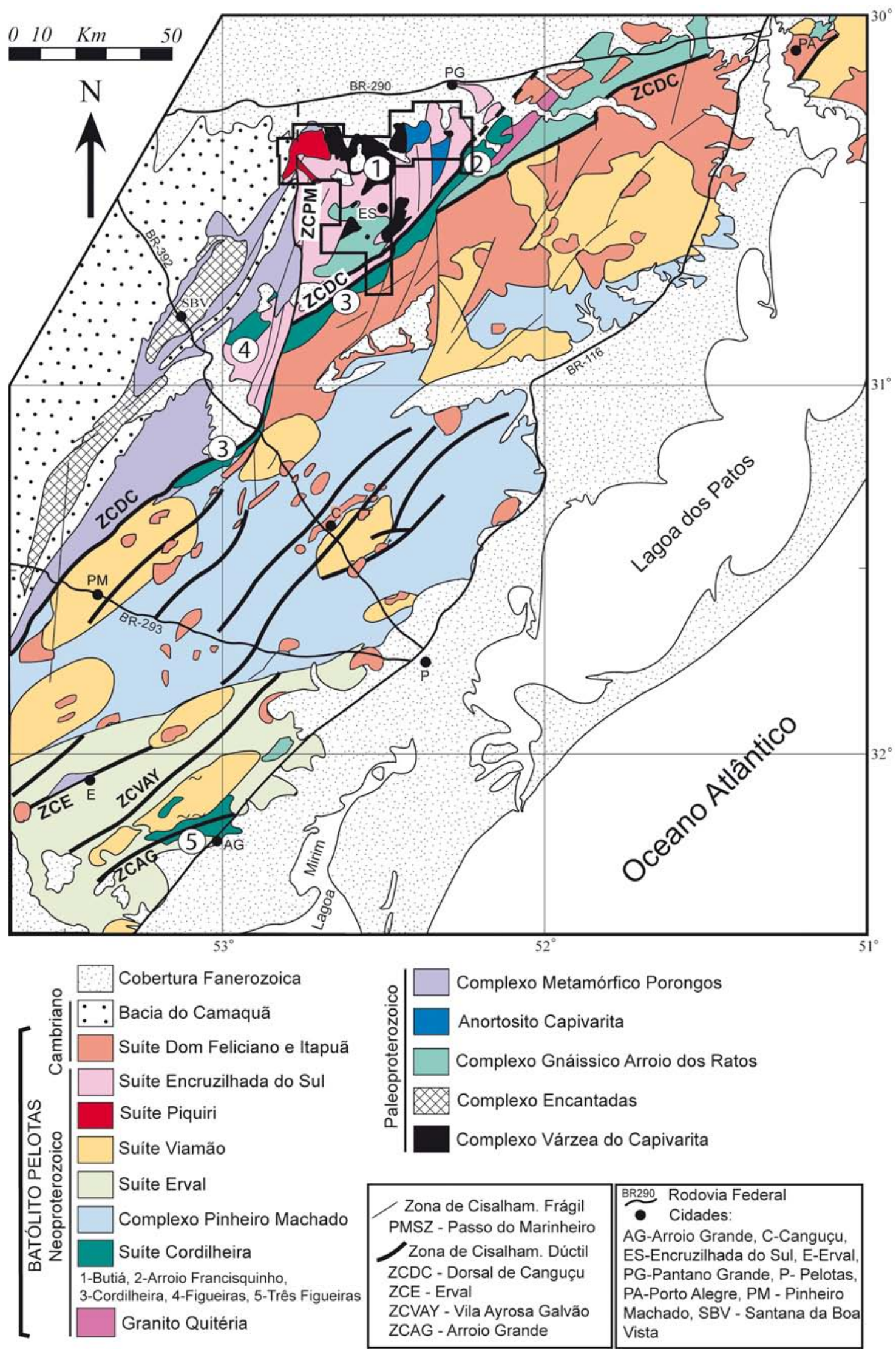

Figura 2. Mapa geológico do Batólito Pelotas. Granitos da Suíte Cordilheira: 1 - Granito Butiá, 2 - Granito Arroio Francisquinho, 3 - Granito Cordilheira, 4 - Granito Figueiras e 5 - Granito Três Figueiras. 0 molde indica a área da figura 3. Modificado de Philipp et al. (2013). 


\section{2 Área, materiais e métodos}

\subsection{Contexto geotectônico}

A região estudada faz parte do Setor Meridional da Província Mantiqueira (Almeida, 1977; Almeida et al., 1981), correspondendo ao Sistema Brasiliano Sudeste, a qual é interpretada como o resultado de diversas colagens orogênicas diacrônicas de distintas unidades geotectônicas durante o Neoproterozoico-Cambriano, formando o setor oeste do paleocontinente Gondwana (Ribeiro \& Fantinel, 1978; Fragoso-Cesar, 1991; Chemale Jr., 2000; Heilbron et al., 2004, Hartmann et al., 2007).

O ESRG é constituído por associações de rochas metamórficas, ígneas e sedimentares dispostas em um complexo arranjo tectono-estratigráfico, controlado e segmentado por zonas de cisalhamento dúcteis de expressão regional de direção $\mathrm{N} 20-40^{\circ}$ e N60-80 $\mathrm{E}$ e N30$-40^{\circ} \mathrm{W}$ (Fig. 1) (Chemale Jr., 2000; Hartmann et al., 2007). Essas unidades se estendem ao sul para o Uruguai e ao norte para Santa Catarina, com ampla correlação geográfica de unidades. A continuidade dessas áreas do CDF é interpretada como a zona de sutura entre os crátons Rio de la Plata e Kalahari (Fragoso-Cesar, 1980; Soliani Jr., 1986; Fragoso-Cesar, 1991; Fernandes et al., 1992).

Os fragmentos do Cráton Rio de la Plata no ESRG ficaram preservados como complexos ortognáissicos de idade paleoproterozoica (Complexo Granulítico Santa Maria Chico, complexos Encantadas, Arroio dos Ratos, Imbicuí e Vigia). A evolução do Cinturão Dom Feliciano está preservada no Terreno São Gabriel pelas associações metavulcano-sedimentares e metaplutônicas relacionadas com a evolução de arcos magmáticos (complexos Cambaí/Cambaizinho, Bossoroca, Palma e Pontas do Salso) gerados e/ou deformados na Orogênese São Gabriel (Chemale Jr., 2000; Hartmann et al., 2007). A evolução final do cinturão ainda está caracterizada pela Orogênese Dom Feliciano, um evento de metamorfismo regional associado à colisão dos crátons Rio de la Plata e Kalahari, entre 650 e 630 Ma (Chemale Jr. et al, 2011; Bom, 2011; Bom et al., 2012). Após o pico do metamorfismo colisional seguiu-se intensa granitogênese de caráter pós-colisional (Fig. 2) (Bitencourt \& Nardi, 2000; Philipp et al., 2000, 2007; Philipp \& Machado, 2005).

O Complexo Várzea do Capivarita foi definido por Frantz et al. (1984) como Complexo Metamórfico Várzea do Capivarita (CMVC), constituído por paragnaisses aluminosos, calci-silicáticos e quartzo-feldspáticos, além do Metanortosito Capivarita e de ortognaisses granodioríticos a tonalíticos subordinados. Os gnaisses para- e ortoderivados foram incluídos na mesma unidade devido à coerência metamórfica e estrutural da associação. Os autores determinaram cinco fases de deformação para o complexo e sugeriram que o mesmo pertencia a um terreno de alto grau. Fernandes et al. (1988) separaram os ortognaisses, incluídos no Complexo Gnáissico Arroio dos Ratos (CGAR), que teria uma relação intrusiva nos paragnaisses, renomeados de Suíte Metamórfica Várzea do Capivarita. Esses autores determinaram duas fases de deformação: D1 (direção E-W) e D2 (direção NE-SW). Martil (2007) apontou similaridades estruturais entre o SMVC e o CGAR, interpretando-as como originadas durante um mesmo evento deformacional final, o que impossibilitou a definição da estratigrafia relativa apenas por métodos de campo. Consequentemente, a relação intrusão/encaixante definida por Fernandes et al. (1988) para as rochas ortoe paraderivadas da região de Encruzilhada do Sul não pôde ser observada. Martil (2010) e Martil et al. (2011) incluíram ortognaisses tonalíticos e graníticos à SMVC redefinida como CMVC, em parte retornando a proposição de Frantz et al. (1984). Na área de estudo desses autores, a alta intensidade da deformação intercalou lascas muito finas entre metassedimentos e ortognaisses, não permitindo uma separação litoestratigráfica em escala adequada. Neste trabalho propõe-se o uso do Complexo Várzea do Capivarita (CVC) para a unidade paraderivada, consistindo de paragnaisses aluminosos, mármores, gnaisses calci-silicáticos e quartzo-feldspáticos (metarenitos quartzosos), não incluindo os ortognaisses do Complexo Arroio dos Ratos ou os corpos de leucogranitos peraluminosos. Essa proposta tem como base a ampla continuidade física entre as associações para- e ortoderivadas e a distinta variação composicional de ambas as sequências.

$\mathrm{Na}$ área de estudo, o CVC encontra-se isolado no interior do Granito Encruzilhada do Sul, aflorando em três áreas contínuas principais: nordeste, norte e sul (Fig. 3). 0 setor nordeste tem a menor expressão, ocorrendo como um corpo com cerca de $8 \times 6 \mathrm{~km}^{2}$. A exposição do setor norte ocupa uma área de aproximadamente $14 \times 8 \mathrm{~km}^{2}$. No setor sul ocorre o maior corpo, com cerca de $12 \times 12 \mathrm{~km}^{2}$, além de outras áreas menores adjacentes às principais.

A metodologia utilizada envolveu o mapeamento geológico e trabalhos de campo para coleta de dados estruturais, reunião de dados estruturais existentes, análise petrográfica, construção de seções geológicas e croquis de detalhe dos afloramentos representativos do complexo.

\section{Resultados}

\subsection{Geologia do Complexo Várzea do Capivarita}

Os gnaisses do Complexo Várzea do Capivarita afloram como raros lajeados em drenagens, cortes de estrada muito alterados e como campos de matacões de pequena dimensão. Estão em contato tectônico com os ortognaisses do Complexo Arroio dos Ratos, com os quais possuem concordância estrutural, o que não permite estabelecer idade relativa entre ambos complexos (Martil, 2007, 2010; Martil et al., 2011). 0 Granito Encruzilhada é intrusivo e os gnaisses ocorrem como roof pendants e xenólitos no interior do granito (Fig. 3). 


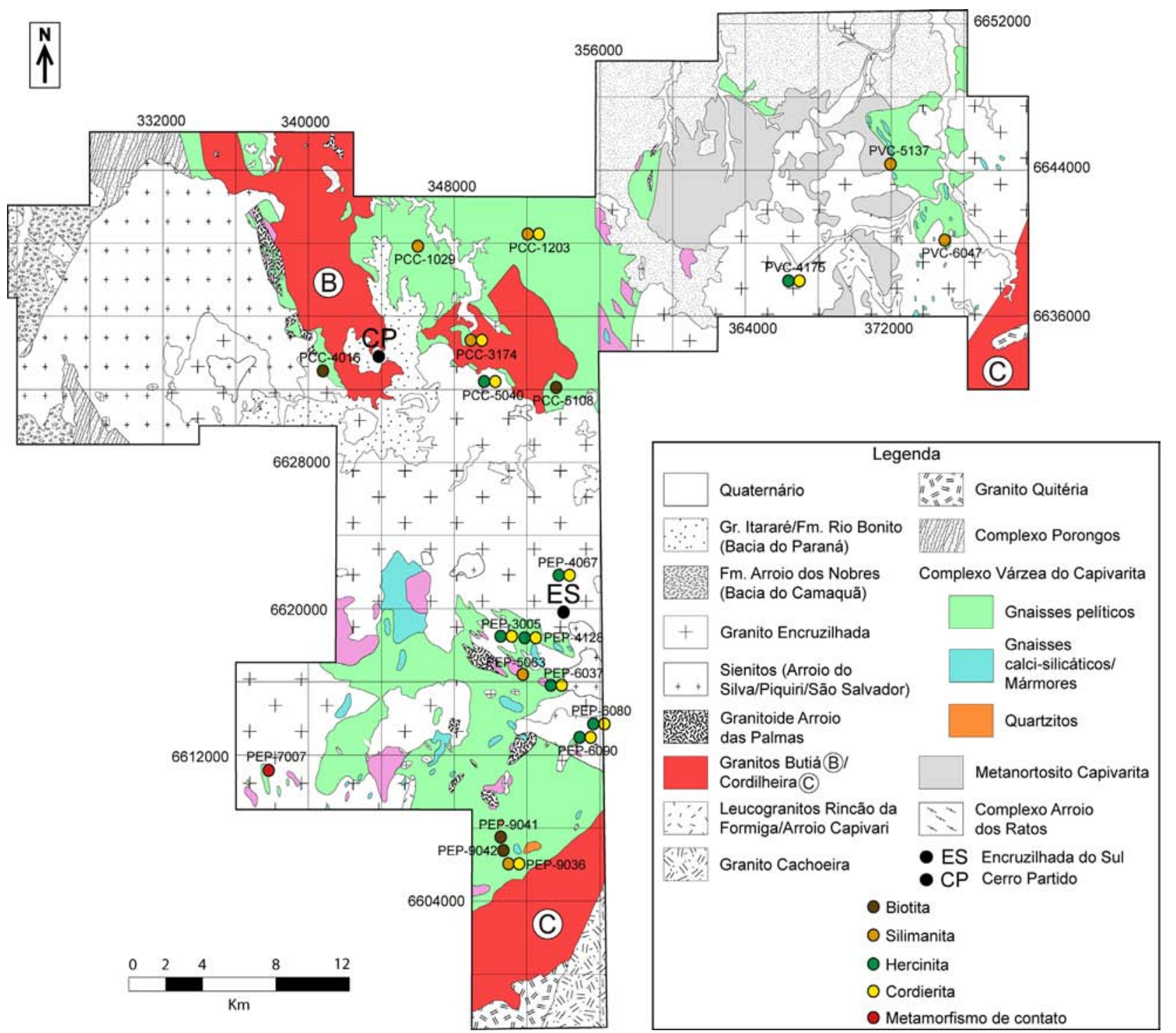

Figura 3. Mapa geológico do Complexo Várzea do Capivarita. Modificado de UFRGS (2008, 2009, 2010, 2011).

O Complexo Várzea do Capivarita é composto por rochas supracrustais metamorfisadas na fácies anfibolito superior e granulito de alta temperatura (UAT, ultra-alta temperatura), incluindo gnaisses pelíticos e, subordinadamente, gnaisses calci-silicáticos, mármores e gnaisses quartzo-feldspáticos (metarcóseos ricos em quartzo e plagioclásio) e raros quartzitos. Os paragnaisses ainda encontram-se injetados por corpos de leucogranitos ricos em muscovita e/ou biotita que têm ampla concordância estrutural com o bandamento dos gnaisses. Esses corpos possuem espessuras variáveis desde 1 a 10 centímetros até espessuras entre 5 e 50 metros ou mais. 0 maior desses corpos de leucogranitos foi individualizado como Granito Butiá por Niessing (2008) e Niessing et al. (2008), destacando no mesmo a ocorrência de agregados de silimanita magmática associadas a biotita.

Os contatos entre os leucogranitos e os gnaisses são bem definidos e as formas interlobadas a curvilíneas são sugestivas de colocação em condições muito dúcteis. As injeções leucograníticas foram interpretadas como produto da migmatização dos gnaisses pelíticos (Silva et al., 2002; Gross et al., 2006; Philipp et al.,
2009; Bom, 2011; Bom et al., 2012; Philipp et al, 2013). Os gnaisses pelíticos são a principal unidade e tem como estrutura principal um bandamento composto, gerado em parte pela segregação metamórfica, e em parte, associado a bandas félsicas constituídas por injeções leucograníticas (Fig. 4). As estruturas variam desde xistosidade bem definida pelo alinhamento de biotita, evoluindo para bandamento irregular, caracterizado por bandas félsicas descontínuas ricas em quartzo e feldspatos, acompanhados por silimanita, cordierita e hercinita, e níveis máficos ricos em biotita e granada. 0 bandamento de segregação metamórfica é irregular e descontínuo, com espessuras em geral milimétricas. As bandas máficas são dominantes e possuem espessuras entre 1 e $10 \mathrm{~mm}$ e composição rica em biotita, contendo comumente almandina e silimanita, constituindo as texturas lepidoblástica e nematoblástica. Os níveis félsicos possuem composição quartzo-feldspática e textura granoblástica inequigranular interlobada, caracterizada por plagioclásio, microclínio e quartzo, acompanhados comumente por níveis à base de cordierita e hercinita. 

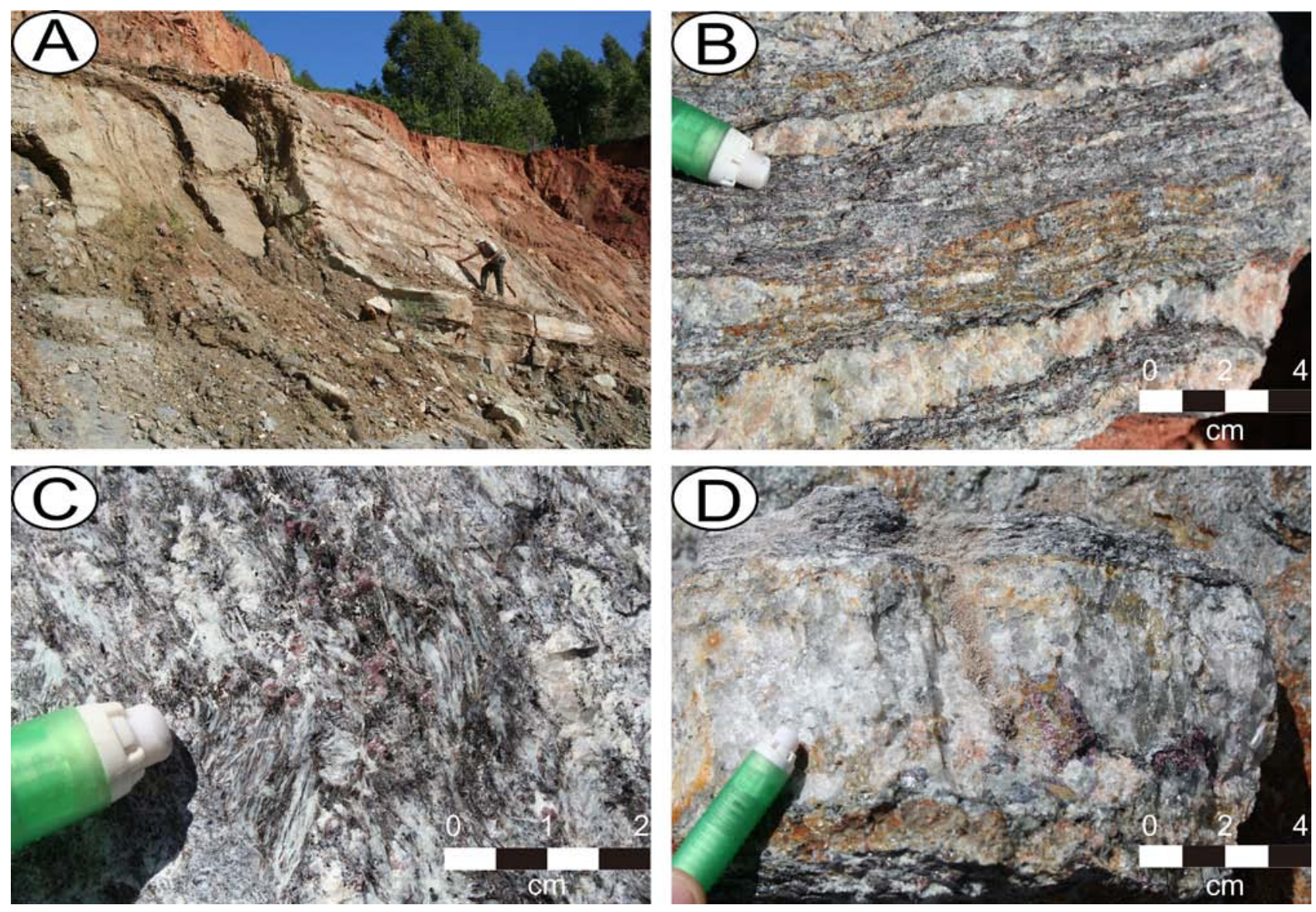

Figura 4. Estruturas macroscópicas dos gnaisses pelíticos do CVC. A) Dobras parasíticas em flanco de dobra antiforme $\mathrm{F}_{3:}$ B) Bandamento gnáissico composto mostrando o bandamento de segregação metamórfica, representado por bandas finas e contínuas, e bandas leucocráticas mais espessas marcadas por injeções graníticas relacionadas à fusão parcial; C) Detalhe do bandamento metamórfico ressaltando porfiroblastos rosados de almandina e cristais aciculares e brancos de silimanita; D) Detalhe das injeções leucograníticas ressaltando a estrutura maciça e os cristais peritéticos de almandina.

As exposições mais ao norte contêm bandamento composto bem definido pela presença de teores variáveis de injeções leucograníticas com texturas equigranulares a pegmatoides. Nessa área afloram injeções de corpos leucograníticos com espessuras de até dezenas de metros, cujo corpo principal foi individualizado e definido como Granito Butiá (Niessing, 2008; Niessing et al., 2008).

Nas exposições do CVC situadas mais ao leste-sudeste, os gnaisses peliticos também possuem injeções de pequenos corpos tabulares de leucogranitos peraluminosos concordantes com o bandamento dos gnaisses (Fig. 5). Esses corpos têm espessuras variáveis desde milimétricas até cerca de 10 metros ou mais, constituindo o componente de injeção dos gnaisses migmatíticos. Os leucogranitos possuem cor esbranquiçada com pontos de cor cinza chumbo definidos por cristais de muscovita e pontos pretos dados pela biotita. Alguns corpos possuem cristais rosados de almandina. A estrutura dos leucogranitos varia de maciça a foliada e está marcada pela orientação de biotita e/ou muscovita e pelo alongamento de quartzo. A textura é equigranular hipidiomórfica média (1 a $3 \mathrm{~mm}$ ) a grossa $(0,5$ a $2 \mathrm{~cm})$.

Os gnaisses calci-silicáticos e os mármores constituem corpos lenticulares ainda preservados, cobrindo áreas com extensões entre 50 e $10.000 \mathrm{~m}^{2}$ e espessura de cerca de poucos metros. Os gnaisses calci-silcáticos têm cor esverdeada e estrutura bandada, alternando níveis mais escuros, contínuos e irregulares ricos em diopsídio e/ou hornblenda, com níveis félsicos ricos em plagioclásio e quartzo, com teores variáveis de microclínio. Os níveis possuem espessuras entre 2 a 10 $\mathrm{mm}$ até 2 a $7 \mathrm{~cm}$ (Fig. 6). Associados aos níveis máficos ainda ocorrem titanita, apatita e granada do tipo grossulária, além de minerais do grupo do epidoto como pistacita e zoizita.

Os mármores são de composição dolomítica silicosa em sua maioria, ocorrendo também mármores calcíticos. Possuem cor em geral branca a cinza, variando a cinza esverdeada, e estrutura maciça; entretanto, observam-se restos de seu acamamento original preservados pela intercalação de camadas contínuas de mármores calcíticos, dolomíticos silicosos e gnaisses calci-silicáticos (Fig. 6). Os principais minerais são calcita e dolomita, ocorrendo ainda diopsídio e olivina nos níveis dolomíticos silicosos e plagioclásio, quartzo, hornblenda, diopsídio, titanita, grossulária e K-feldspato nos gnaisses calci-silicáticos. Durante o posicionamento do Granito Encruzilhada, esses mármores foram afetados pelo calor da intrusão e por fluidos hidrotermais que geraram reações retrometamórficas como serpentinização de olivina e transformação do piroxênio em agregados de clorita e anfibólio. 

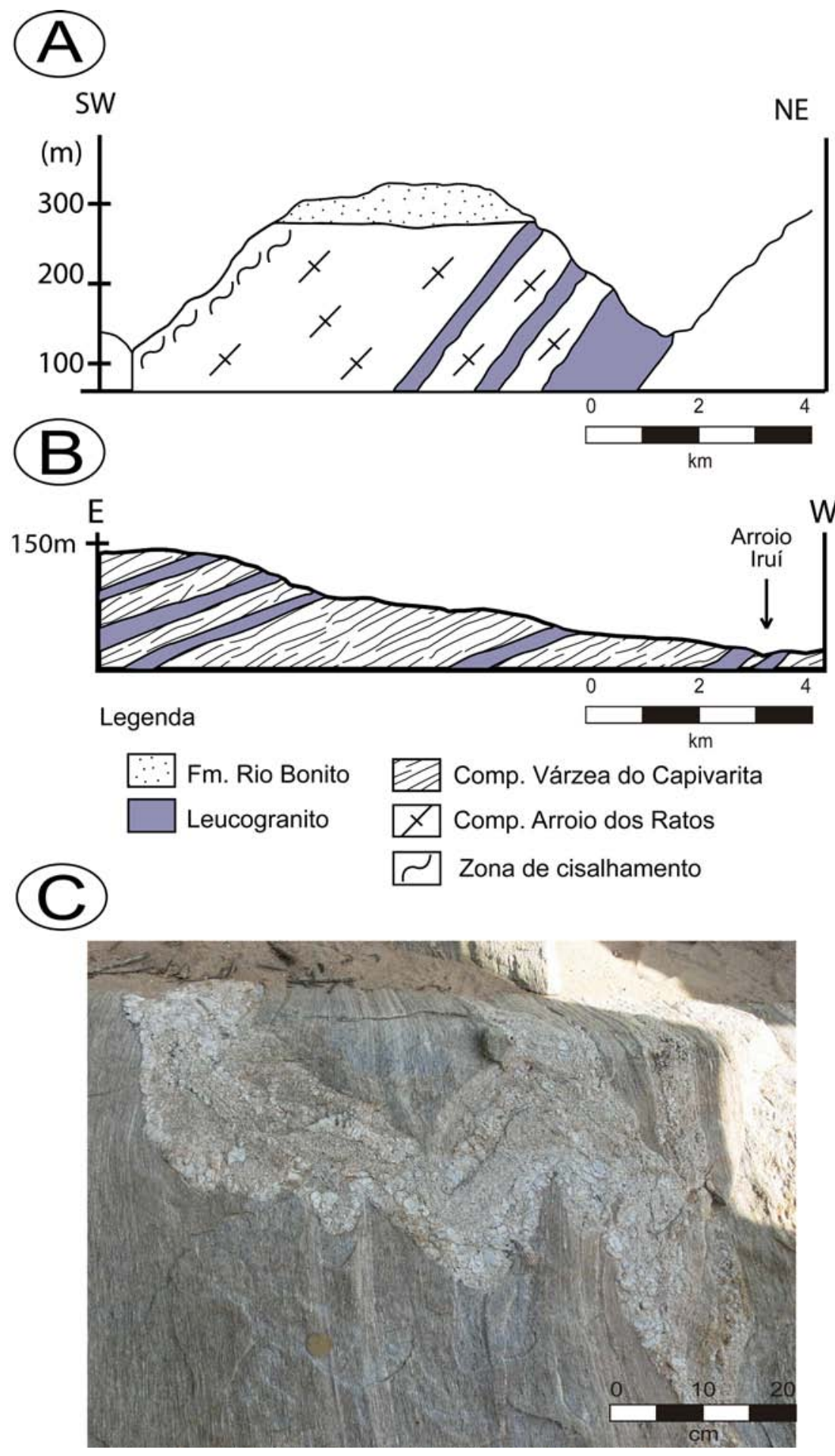

Figura 5. Seções geológicas e fotografia de afloramentos na região leste-sudeste da área de estudo. A) Seção geológica esquemática mostrando a intercalação de corpos leucograníticos correlatos ao Granito Butiá cortando os gnaisses do Complexo Arroio dos Ratos na região ao sul do Cerro Partido; B) Seção geológica esquemática mostrando a intercalação de corpos leucograníticos com os gnaisses pelíticos do CVC na região ao sul do Cerro Partido; C) Detalhe em planta de afloramento de lajeado no arroio Iruí, destacando o dobramento de injeção de leucogranito afetada pelo desenvolvimento da foliação $\mathrm{S}_{2}$. 

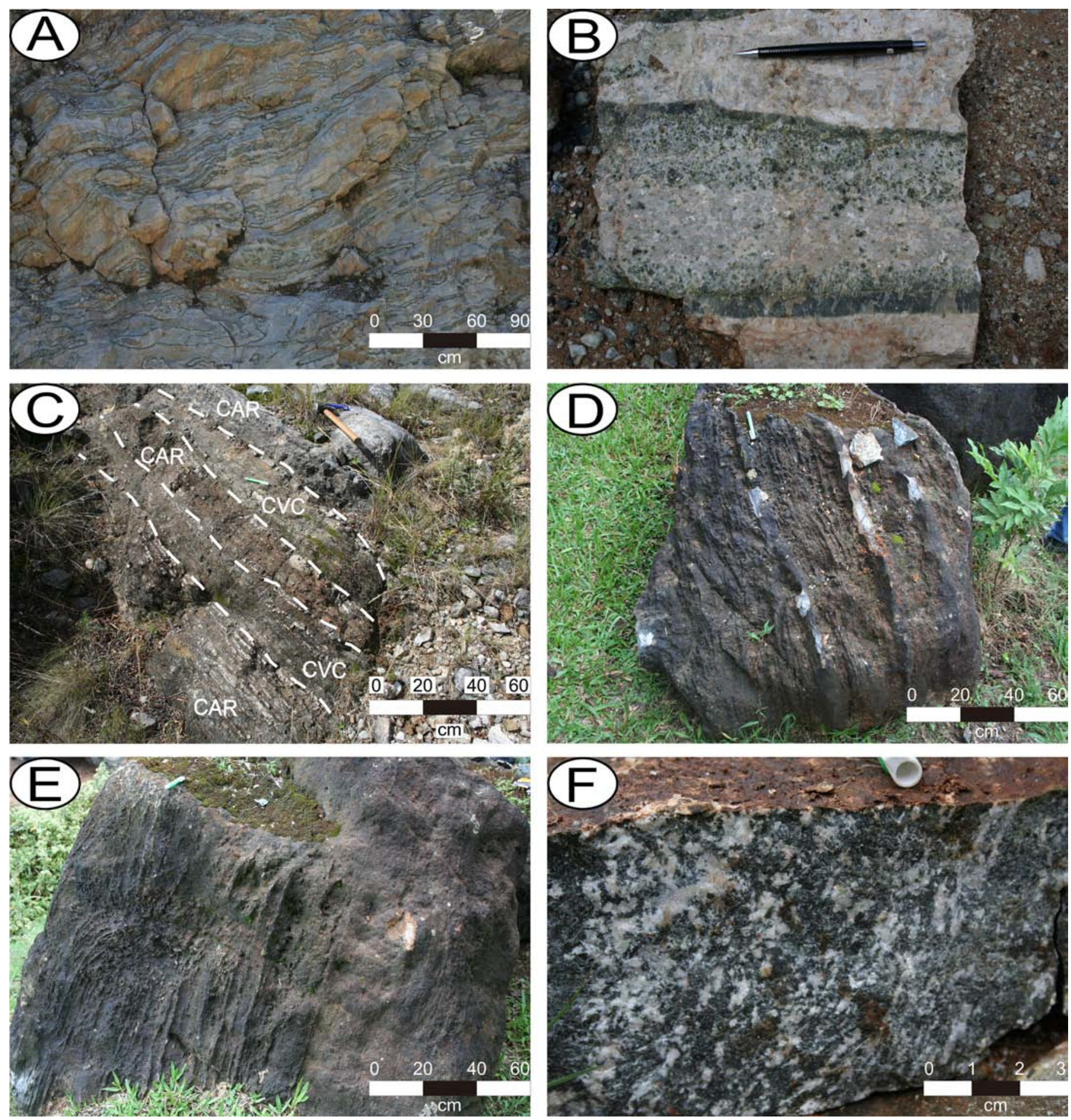

Figura 6. Principais feições macroscópicas dos mármores e gnaisses calci-silicáticos. A) Acamamento sedimentar $\mathrm{S}_{0}$ definido por variação composicional em mármore; B) Detalhe do acamadamento ressaltando uma camada de olivina mármore e destacando a presença de olivina verde serpentinizada; C) Gnaisse cálci-silicático bandado intercalado com bandas de ortognaisse do CAR com mergulho oblíquo; D-E) Gnaisse calci-silicático com bandamento irregular e contínuo definido por diferenças composicionais; F) Detalhe do bandamento do gnaisse calci-silicático destacando níveis irregulares ricos em plagioclásio e diopsídio.

\subsection{Petrografia}

\subsubsection{Paragnaisses}

Os gnaisses pelíticos são classificados como K-feldspato-granada-biotita-silimanita gnaisses, granada- cordierita-biotita-silimanita gnaisses, granada-silimanita-biotita gnaisses e hercinita-cordierita-granada-silimanita-biotita gnaisses (Tab. 1). Os gnaisses calci-silicáticos são classificados como diopsídio-hornblenda gnaisses, quartzo-diopsídio-K-feldspato gnaisses e quartzo-grossulária-diopsídio gnaisses. Subordinadamente ocorrem quartzitos, gnaisses quartzo-feldspáticos (metarcóseos ricos em quartzo e plagioclásio) e mármores. Os mármores puros são ricos em calcita. Os mármores dolomíticos silicosos são classificados como olivina mármores, diopsídio mármores e olivina-diopsídio mármores. 
Tabela 1. Análises modais com os principais minerais encontrados nos gnaisses pelíticos do Complexo Várzea do Capivarita. Abreviações: Alm - almandina, Ap - apatita, Bt - biotita, Chl - clorita, Crd - cordierita, Hc - hercinita, Mc - microclínio, Ms - muscovita, Op - opacos, Pl plagioclásio, Qtz - quartzo, Sil - silimanita, Zr - zircão.

\begin{tabular}{|c|c|c|c|c|c|c|c|c|c|c|c|c|c|c|c|}
\hline $\begin{array}{l}\text { Amostra / } \\
\text { Mineral }\end{array}$ & Qtz & Mc & $\mathrm{Pl}$ & $\mathrm{Bt}$ & Alm & Sil & Crd & $\mathrm{Hc}$ & Ms & Chl & Op & Tit & $\mathrm{Zr}$ & Ap & Classificação \\
\hline PCC-1029A & 45 & 5 & 8 & 35 & 5 & - & 1 & - & 1 & - & $\mathrm{Tr}$ & - & $\operatorname{Tr}$ & $\operatorname{Tr}$ & Crd-alm-mc-bt gnaisse \\
\hline PCC-1203 & 43 & 5 & 15 & 15 & 7 & 5 & 10 & - & - & - & $\operatorname{Tr}$ & $\operatorname{Tr}$ & $\operatorname{Tr}$ & $\operatorname{Tr}$ & $\begin{array}{l}\text { Mc-sil-alm-crd-bt } \\
\text { gnaisse }\end{array}$ \\
\hline PCC-3174A & 37 & 15 & 10 & 10 & 6 & 7 & 10 & - & 2 & - & 3 & - & $\operatorname{Tr}$ & $\operatorname{Tr}$ & $\begin{array}{l}\text { Alm-sil-bt-crd-mc } \\
\text { gnaisse }\end{array}$ \\
\hline PCC-3174B & 44 & 20 & 10 & 15 & 2 & 1 & 7 & - & - & - & 1 & - & $\operatorname{Tr}$ & $\operatorname{Tr}$ & $\begin{array}{l}\text { Sil-alm-crd-bt-mc } \\
\text { gnaisse }\end{array}$ \\
\hline PCC-4016A & 36 & 13 & 7 & 42 & 2 & - & - & - & - & - & $\operatorname{Tr}$ & - & $\operatorname{Tr}$ & $\operatorname{Tr}$ & Alm-mc-bt gnaisse \\
\hline PCC-5040 & 45 & 3 & 10 & 10 & 4 & 2 & 20 & 1 & 2 & - & 3 & - & $\operatorname{Tr}$ & $\operatorname{Tr}$ & $\begin{array}{l}\text { Hc-sil-alm-bt-crd } \\
\text { gnaisse }\end{array}$ \\
\hline PCC-5108B & 28 & 17 & 17 & 33 & 5 & - & - & - & - & - & $\operatorname{Tr}$ & - & $\operatorname{Tr}$ & $\operatorname{Tr}$ & Alm-mc-bt gnaisse \\
\hline PEP-3005A & 44 & 10 & 16 & 16 & 5 & 3 & 3 & 1 & - & - & 2 & - & $\operatorname{Tr}$ & $\operatorname{Tr}$ & $\begin{array}{l}\text { Hc-sil-crd-alm-bt } \\
\text { gnaisse }\end{array}$ \\
\hline PEP-4067 & 40 & 5 & 10 & 5 & 5 & 15 & 15 & 3 & - & - & 2 & - & $\operatorname{Tr}$ & $\operatorname{Tr}$ & $\begin{array}{l}\text { Hc-bt-alm-sil-crd } \\
\text { gnaisse }\end{array}$ \\
\hline PEP-4128B & 36 & 2 & 10 & 15 & 6 & 8 & 15 & 5 & - & - & 3 & - & $\operatorname{Tr}$ & $\operatorname{Tr}$ & $\begin{array}{l}\text { Hc-alm-sil-bt-crd } \\
\text { gnaisse }\end{array}$ \\
\hline PEP-4128C & 39 & 7 & 15 & 15 & 5 & 10 & 5 & 4 & - & - & $\operatorname{Tr}$ & - & $\operatorname{Tr}$ & $\operatorname{Tr}$ & $\begin{array}{l}\text { Hc-alm-crd-sil-bt } \\
\text { gnaisse }\end{array}$ \\
\hline PEP-5063B & 31 & 13 & 8 & 25 & 7 & 13 & - & - & - & - & 3 & - & $\operatorname{Tr}$ & $\operatorname{Tr}$ & Alm-mc-sil-bt gnaisse \\
\hline PEP-6037A & 31 & 9 & 11 & 10 & 8 & 7 & 18 & 1 & - & - & 5 & - & $\operatorname{Tr}$ & $\operatorname{Tr}$ & $\begin{array}{l}\text { Hc-sil-alm-bt-crd } \\
\text { gnaisse }\end{array}$ \\
\hline PEP-6090C & 20 & 6 & 7 & 20 & 5 & 2 & 20 & 5 & 4 & 6 & 5 & - & $\operatorname{Tr}$ & $\operatorname{Tr}$ & $\begin{array}{l}\text { Sil-alm-hc-bt-crd } \\
\text { gnaisse }\end{array}$ \\
\hline PEP-9036D & 17 & 20 & 16 & 30 & 8 & 4 & 5 & - & - & - & $\operatorname{Tr}$ & - & $\operatorname{Tr}$ & $\operatorname{Tr}$ & $\begin{array}{l}\text { Sil-crd-alm-mc-bt } \\
\text { gnaisse }\end{array}$ \\
\hline PEP-9041A & 36 & 15 & 10 & 26 & 5 & - & - & - & 7 & - & 1 & - & $\operatorname{Tr}$ & $\operatorname{Tr}$ & Alm-mc-bt gnaisse \\
\hline PEP-9042 & 73 & 5 & 10 & 5 & - & - & - & - & 5 & - & 2 & - & $\operatorname{Tr}$ & $\operatorname{Tr}$ & Bt-mc-qtz gnaisse \\
\hline PVC-4175D & 26 & 12 & 5 & 15 & 3 & 10 & 15 & 3 & 1 & - & 10 & - & $\operatorname{Tr}$ & $\operatorname{Tr}$ & $\begin{array}{l}\text { Hc-crd-alm-sil-bt } \\
\text { gnaisse }\end{array}$ \\
\hline PVC-5137B & 28 & 6 & 9 & 22 & 17 & 17 & - & - & - & 1 & - & - & $\operatorname{Tr}$ & $\operatorname{Tr}$ & Mc-alm-sil-bt gnaisse \\
\hline PVC-6047A & 20 & 15 & 5 & 24 & 20 & 15 & - & - & $\operatorname{Tr}$ & - & 1 & - & $\operatorname{Tr}$ & $\operatorname{Tr}$ & Sil-gt-bt gnaisse \\
\hline
\end{tabular}

Tabela 2. Análises modais com os principais minerais encontrados nos mármores e gnaisses calci-silicáticos do Complexo Várzea do Capivarita. Abreviações: Ap - apatita, Carb - carbonatos, Chl - clorita, Di - diopsídio, Grs - grossulária, Kfs - K-feldspato, Ol - olivina, Op - opacos, Pl - plagioclásio, Qtz - quartzo, Tit - titanita, Trem - tremolita, Zr - zircão.

\begin{tabular}{|c|c|c|c|c|c|c|c|c|c|c|c|c|c|c|}
\hline $\begin{array}{l}\text { Amostra / } \\
\text { Mineral }\end{array}$ & Carb & $\mathrm{Pl}$ & Ol & $\mathrm{Di}$ & Trem & Qtz & Kfs & Tit & Grs & Ap & Op & Chl & $\mathrm{Zr}$ & Classificação \\
\hline $\begin{array}{l}\text { PEP- } \\
\text { 2099A1 }\end{array}$ & 50 & - & 5 & 20 & - & 10 & - & 5 & 5 & 0.5 & 0.5 & - & $\operatorname{Tr}$ & $\begin{array}{l}\text { Grs-tit-ol-qtz-di } \\
\text { mármore }\end{array}$ \\
\hline $\begin{array}{l}\text { PEP- } \\
\text { 2099A2 }\end{array}$ & 2 & - & - & 30 & 2 & 21 & 38 & 2 & 3 & 1.5 & 0.5 & - & $\operatorname{Tr}$ & $\begin{array}{l}\text { Grs-tit-qtz-di-Kf } \\
\text { gnaisse }\end{array}$ \\
\hline $\begin{array}{l}\text { PEP- } \\
2099 \mathrm{~B}\end{array}$ & 45 & - & 5 & 20 & - & 10 & - & 5 & 5 & 0.5 & 0.5 & - & $\operatorname{Tr}$ & $\begin{array}{l}\text { Grs-tit-ol-qtz-di } \\
\text { mármore }\end{array}$ \\
\hline $\begin{array}{l}\text { PEP- } \\
3048 B\end{array}$ & - & 17 & - & 56 & - & 13 & 9 & 4 & - & 1 & - & - & $\operatorname{Tr}$ & $\begin{array}{l}\text { Tit-Kf-qtz-pl-di } \\
\text { gnaisse }\end{array}$ \\
\hline PVC-5012 & 3 & 20 & - & 65 & - & - & 3 & 4 & - & 1 & - & 4 & $\operatorname{Tr}$ & $\begin{array}{l}\text { Ap-Kf-tit-pl-di } \\
\text { gnaisse }\end{array}$ \\
\hline
\end{tabular}


Os gnaisses pelíticos possuem bandamento composicional gerado por segregação metamórfica, com disposição irregular e descontínua, de espessura em geral milimétrica. As bandas máficas são dominantes e constituídas à base de biotita, com teores variáveis de almandina e silimanita (Fig. 7AB). A orientação dos cristais de biotita caracteriza a textura lepidoblástica média a grossa (1 a $4 \mathrm{~mm}$ ), enquanto a orientação dos cristais de silimanita define textura nematoblástica média a grossa ( 2 a $10 \mathrm{~mm}$ ). Os níveis félsicos possuem composição quartzo-feldspática e textura granoblástica inequigranular interlobada a poligonal média 0,2 a $0,5 \mathrm{~mm}$ ) caracterizada por cristais equidimensionais de plagioclásio, microclínio e quartzo (Fig. 7C). A cordierita comumente ocorre associada em níveis com hercinita e silimanita (Fig. 7D-F). A biotita possui um pleocroísmo de cor castanho-avermelhado, sugestivo do alto teor de Ti e, consequentemente, indicando, do ponto de vista petrográfico, condições metamórficas mínimas de fácies anfibolito médio a superior.
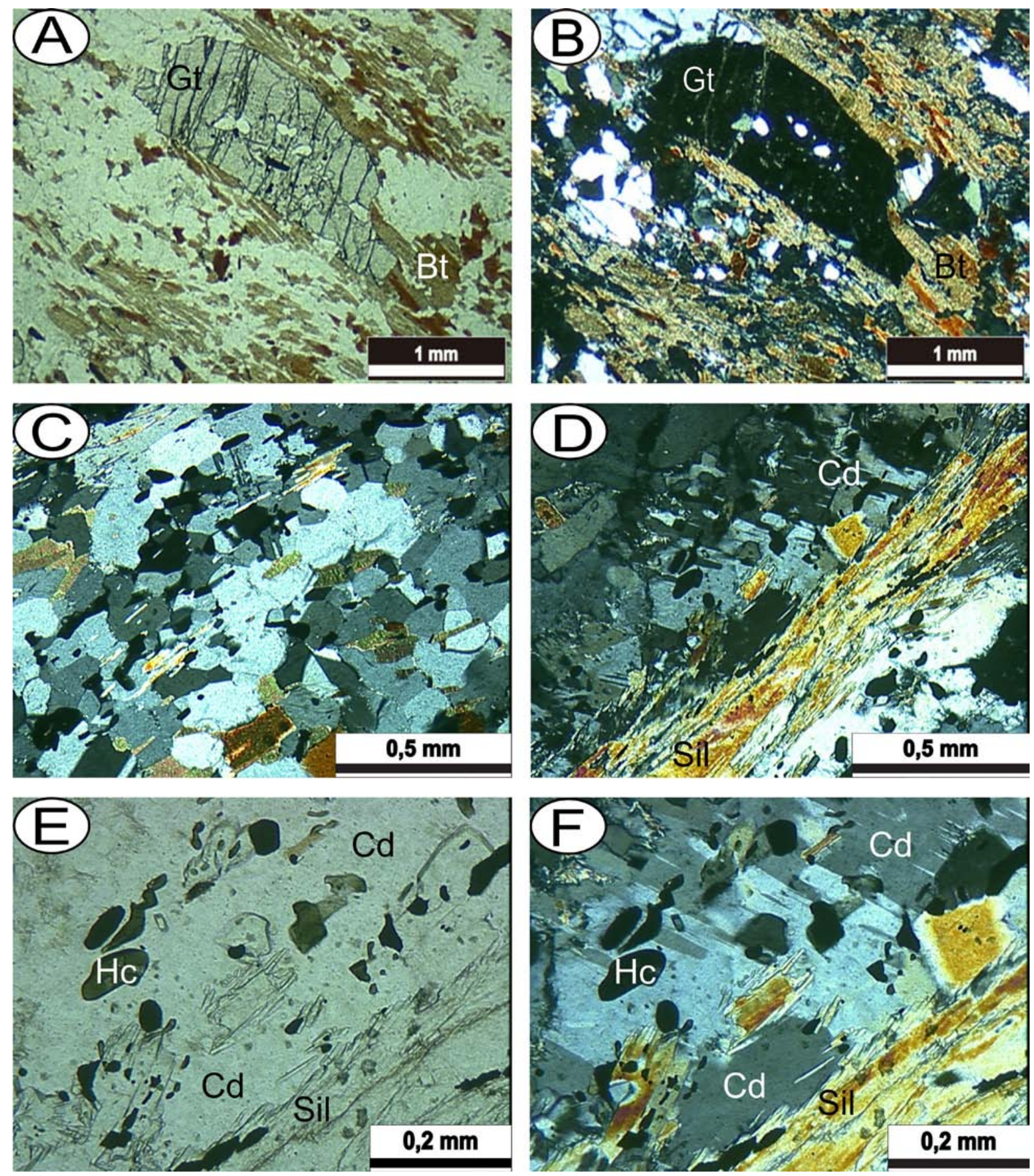

Figura 7. Feições microscópicas dos gnaisses pelíticos do Complexo Várzea do Capivarita. A) Bandamento de segregação metamórfica intercalando níveis ricos em biotita e silimanita com porfiroblastos de almandina e níveis com quartzo-feldspato-cordierita (luz plano-polarizada); B) mesma fotomicrografia com polarizadores cruzados; C) Detalhe da textura granoblástica poligonal dos níveis quartzo-feldspáticos (polarizadores cruzados); D) Detalhe do bandamento ressaltando a intercalação de bandas contínuas de silimanita (Sil) e cordierita (Crd) (polarizadores cruzados); E) Detalhe dos cristais de hercinita ( $\mathrm{Hc}$ ) associados às bandas ricas em cordierita (Crd) e silimanita (Sil) (luz plano-polarizada); F) mesma fotomicrografia com polarizadores cruzados. 
Os mármores possuem composições puras; entretanto, na sua maioria, são mármores dolomíticos silicosos. Os mármores puros contêm estrutura maciça e são compostos à base de calcita, com teores baixos de dolomita, enquanto os mármores dolomíticos silicosos mostram ainda tremolita, diopsídio e olivina. A textura é granoblástica poligonal grossa a muito grossa ( 1 a 10 $\mathrm{mm}$ ) (Fig. 8AB). Os gnaisses calci-silicáticos possuem bandamento composicional de espessura milimétrica a centimétrica ( 5 a $30 \mathrm{~mm}$ ) definido pela alternância de níveis félsicos à base de quartzo e plagioclásio, com microclínio, e níveis máficos ricos em diopsídio, acompanhados por hornblenda, granada grossulária, titanita, apatita e por vezes, epidoto. A textura dominante é granoblástica inequigranular média a grossa $(0,3$ a 1,5 mm) (Fig. 8CD).
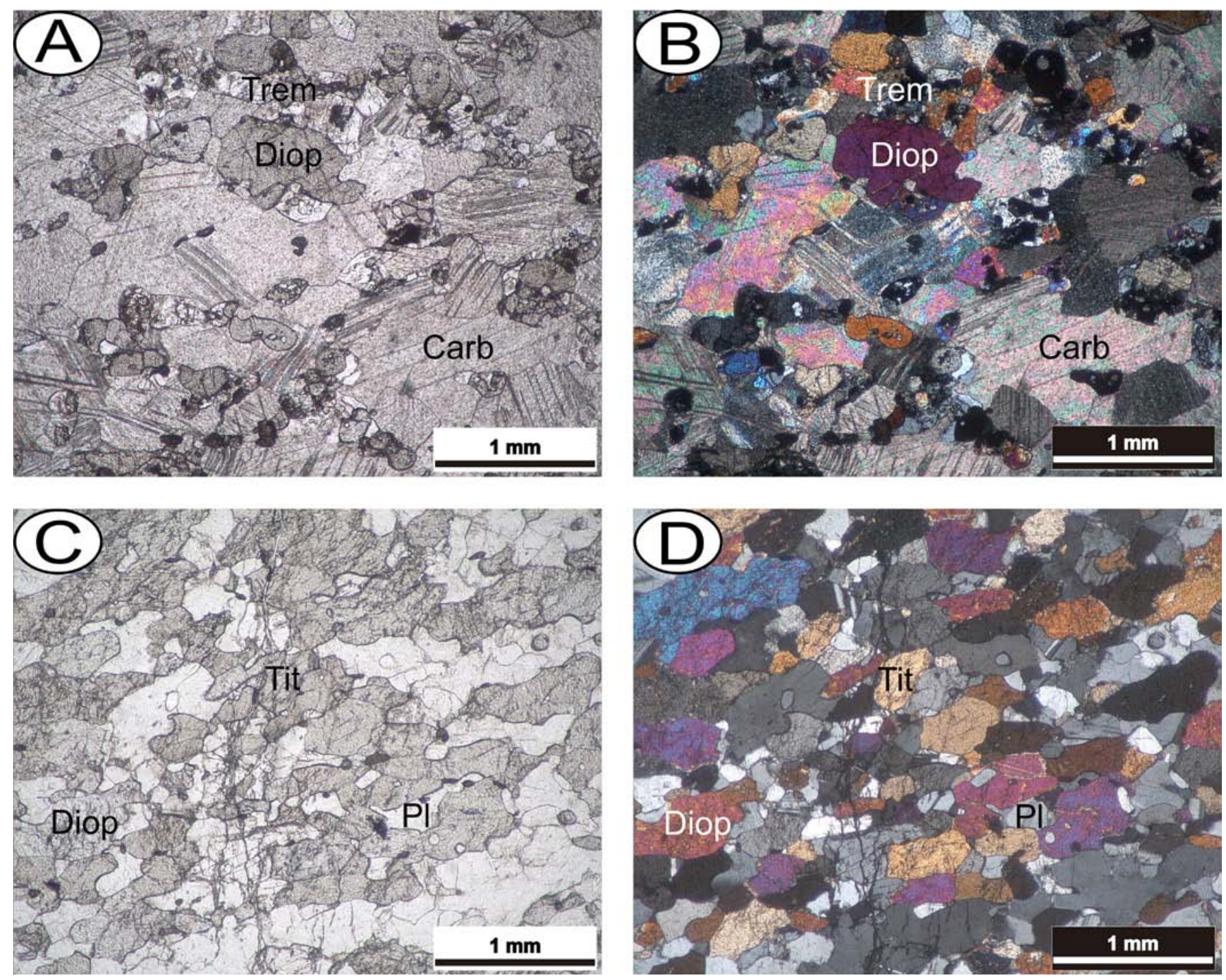

Figura 8. Feições microscópicas dos mármores e gnaisses calci-silicáticos do Complexo Várzea do Capivarita. A) Mármore dolomítico silicoso com diopsídio e tremolita (luz plano-polarizada); B) Mesma fotomicrografia com polarizadores cruzados; C) Bandamento de segregação metamórfica em gnaisse calci-silicático destacando níveis máficos contínuos ricos em diopsídio e titanita (luz plano-polarizada); D) Mesma fotomicrografia com polarizadores cruzados.

\subsubsection{Leucogranitos peraluminosos}

Os gnaisses pelíticos contêm injeções de leucogranitos peraluminosos ricos em quartzo. Esses leucogranitos variam entre sieno e monzogranitos e possuem textura equigranular hipidiomórfica média a grossa (2 a $6 \mathrm{~mm}$ ) caracterizada por cristais tabulares e subédricos de K-feldspato e plagioclásio, com biotita e/ ou muscovita intersticial, quartzo alongado a amebóide e eventualmente almandina (Fig. 9). Sua estrutura é definida por foliação de forma marcada por orientação de agregados de biotita e/ou muscovita e por quartzo alongado. Essa foliação é superposta localmente por foliação milonítica definida pelo estiramento do quartzo com formação de subgrãos alongados com forte extinção ondulante, em parte recristalizado para textura granoblástica inequigranular interlobada a poligonal média $(0,1$ a $0,2 \mathrm{~mm})$. Também se observa o estiramento incipiente da biotita e a formação de subgrãos e extinção ondulante dos feldspatos. Nos cristais de quartzo e microclínio observa-se recristalização dinâmica incipiente marcada por finos agregados granoblásticos nas bordas de porfiroclastos estirados. Os leucogranitos estão concentrados na porção noroeste da área, diminuindo acentuadamente sua ocorrência em direção ao sul e leste da área de exposição do CVC. 

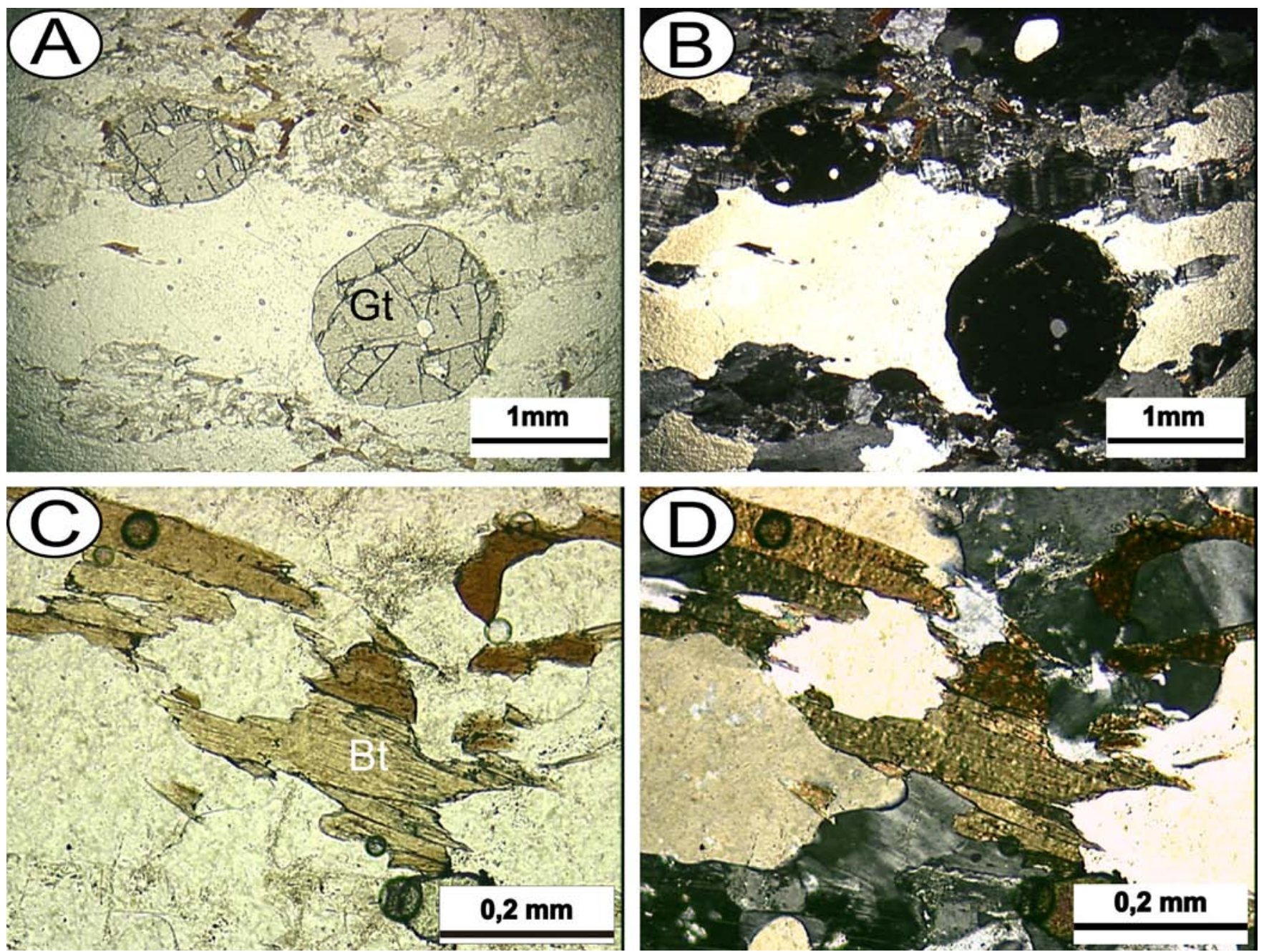

Figura 9. Feições microscópicas dos leucogranitos. A) Foliação magmática definida pela orientação de K-feldspato e plagioclásio e quartzo alongado, destacando a presença de almandina (luz plano-polarizada); B) Mesma fotomicrografia com polarizadores cruzados; C) Detalhe da orientação da biotita (luz plano-polarizada); D) Mesma fotomicrografia com polarizadores cruzados.

\subsection{Geologia estrutural}

As unidades do CVC ainda possuem muitas feições reliquiares parcialmente preservadas. A intercalação composicional observada nos metapelitos e nas rochas calci-silicáticas, bem como a intercalação dos mármores puros e impuros e dos gnaisses calci-silicáticos, representam o acamamento primário preservado $\left(\mathrm{S}_{0}\right)$. Entretanto, a intensa deformação associada à formação do bandamento metamórfico e das zonas de cisalhamento e, principalmente, às diversas fases de dobramento, não permitem a reconstrução da $S_{0}$, exceto em escala de afloramento.

Foram observadas duas foliações metamórficas principais, denominadas $\mathrm{S}_{1}$ e $\mathrm{S}_{2}$, associadas aos eventos metamórficos $\mathrm{M}_{1}$ e $\mathrm{M}_{2}$. $\mathrm{O}$ bandamento principal $\left(\mathrm{S}_{1}\right)$ está afetado por dobras isoclinais desenvolvendo clivagem de crenulação, responsável pela ampla formação da foliação $S_{2}$ em zonas de transposição. As fases de deformação subsequentes geram as dobras $\mathrm{F}_{3}$ e $\mathrm{F}_{4}$, associadas à formação de duas direções principais de clivagens de fratura, que indicam que a sua formação ocorreu em nível crustal mais raso.

\subsubsection{Estruturas do CVC}

As áreas de exposição do CVC estão delimitadas por duas zonas de cisalhamento principais: ao leste pela Zona de Cisalhamento Dorsal de Canguçu (ZCDC), de orientação $\mathrm{N} 50^{\circ} \mathrm{E}$, e ao oeste e ao sul pela Zona de Cisalhamento Passo do Marinheiro (ZCPM), de orientação N-S (Fig. 2). A ZCDC tem caráter dúctil e afeta as rochas regionais, causando intensa transformação milonítica. A ZCPM tem caráter mais tardio, afetando inclusive os milonitos da ZCDC, desenvolvendo processos de deformação rúptil a rúptil-dúctil.

Os dados estruturais integrados de toda a área estudada resultaram em atitude média da foliação metamórfica de $\mathrm{N} 30^{\circ} \mathrm{W}\left(330^{\circ}\right)$, com mergulho médio de $45^{\circ}$ para SW (Fig. 10A). A lineação mineral é sub-horizontal, com caimento médio de $6^{\circ}$ para $\mathrm{N} 30^{\circ} \mathrm{W}$ e $4^{\circ}$ para $S 30^{\circ} \mathrm{E}$ (Fig. 10A). 0 bandamento metamórfico dos gnaisses foi considerado como a foliação $\mathrm{S}_{1}$, a partir da qual as fases de dobramento subsequentes irão acrescentar novas estruturas em ordem crescente. A observação direta em campo permitiu reconhecer a existência de dobras isoclinais intrafoliais $\left(\mathrm{F}_{2}\right)$ associadas a clivagem de crenulação, afetando o bandamento $S_{1}$, com a transposição dessa foliação e geração da foliação $S_{2}$ (Fig. 11). A fo- 
liação ígnea $\left(\mathrm{S}_{0}\right)$ dos leucogranitos peraluminosos e do

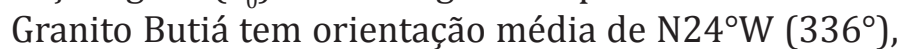
com mergulho médio de $38^{\circ}$ para SW, e a lineação de estiramento possui caimento de $10^{\circ}$ para $S 40^{\circ} \mathrm{E}$ e $4^{\circ}$ para $\mathrm{N} 20^{\circ} \mathrm{W}$ (Fig. $10 \mathrm{~B}$ ). Analisando os dados estrutu- rais, observa-se que o bandamento gnáissico é paralelo à foliação ígnea, o que indica que os leucogranitos peraluminosos (incluindo o Granito Butiá) foram formados pelo menos entre os eventos $D_{1}$ e $D_{2}$ e intrudiram o CVC durante o evento $D_{2}$.

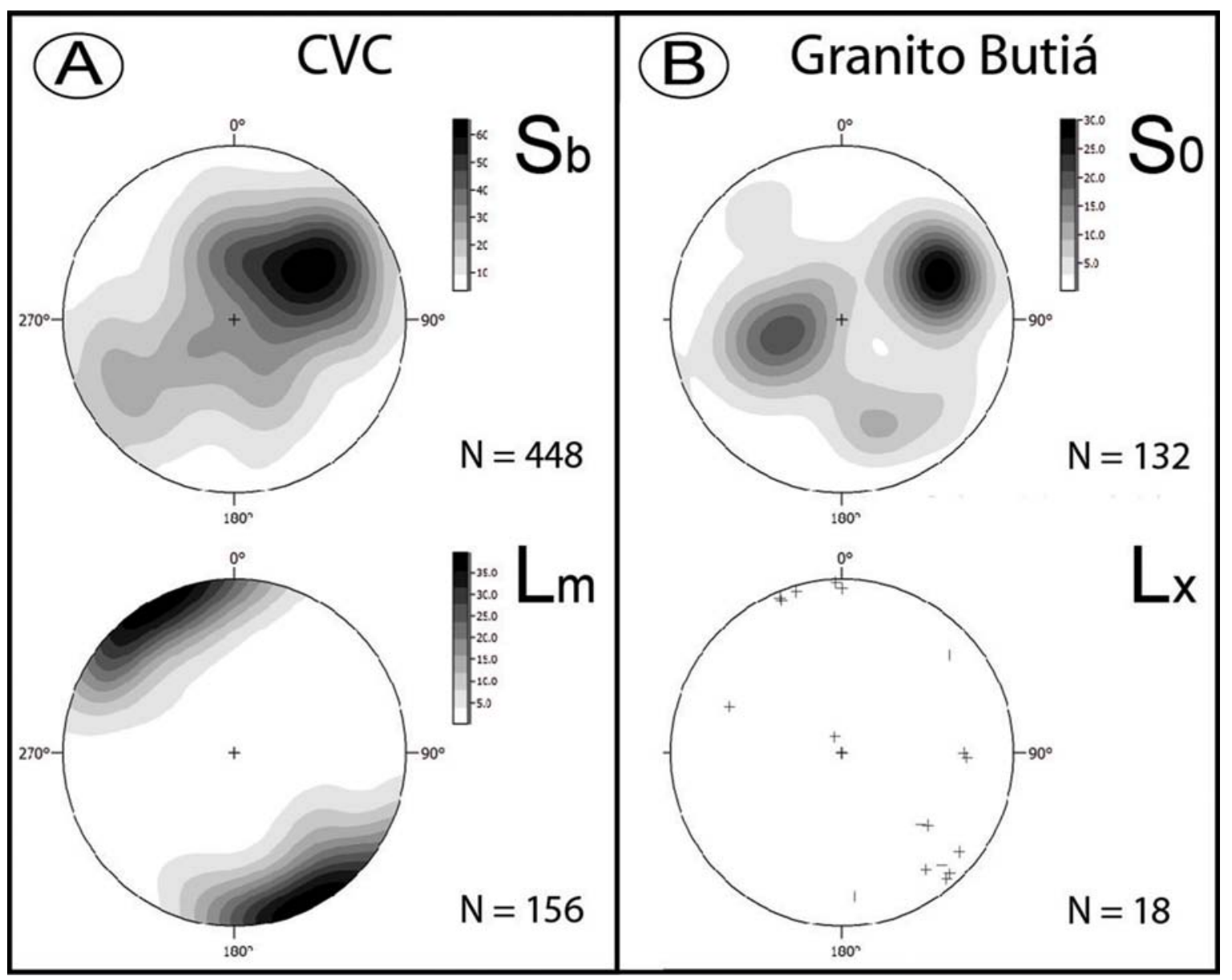

Figura 10. Redes equiárias de Schmidt (hemisfério inferior) representativas das unidades do CVC e dos leucogranitos associados. A) Estereogramas de contagem de polos do bandamento gnáissico e da lineação mineral dos gnaisses do CVC; B) Estereograma de contagem de polos da foliação ígnea e estereograma de polos da lineação de estiramento dos leucogranitos peraluminosos (Granito Butiá).
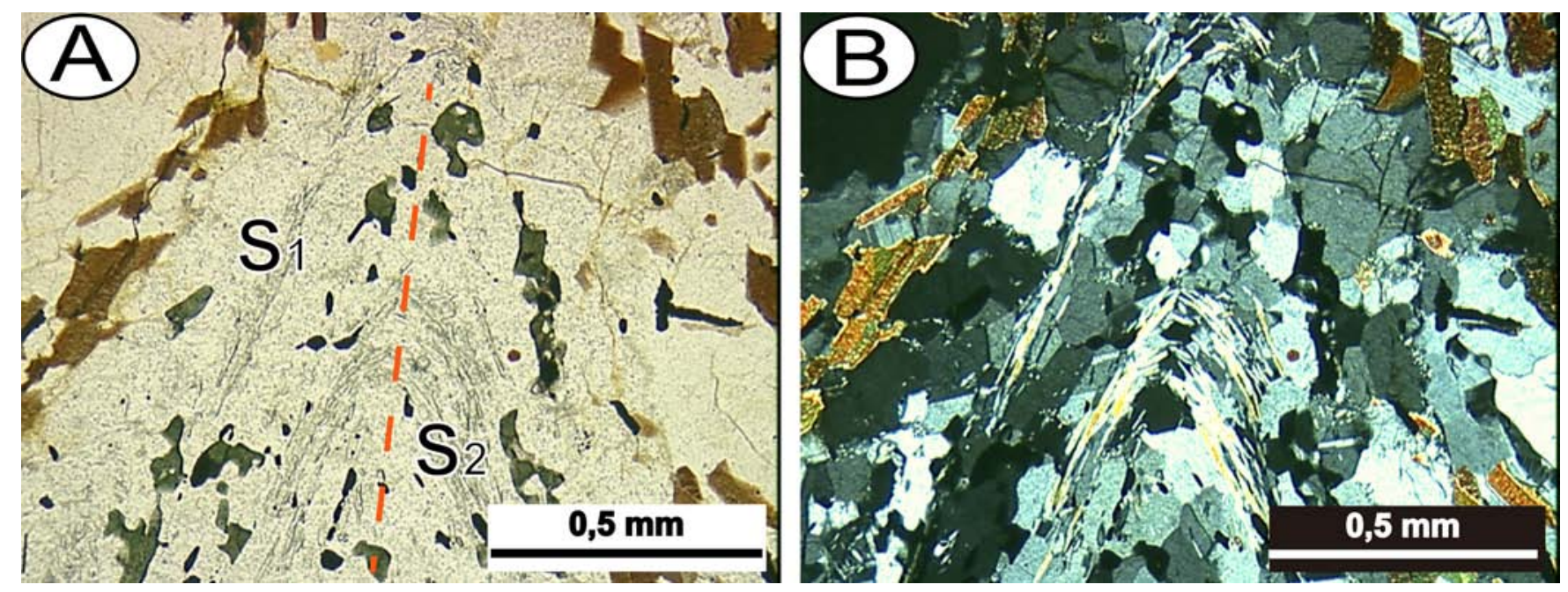

Figura 11. Fotomicrografias de gnaisse pelítico mostrando uma dobra isoclinal $\mathrm{F}_{2}$ afetando o bandamento gnáissico $\mathrm{S}_{1}$, caracterizado pela intercalação de níveis ricos em biotita, silimanita e hercinita e níveis quartzo-feldspáticos, luz plano polarizada (A) e com polarizadores cruzados (B). 
A observação da trajetória geral da foliação nos mapas das figuras 12,13 e 14 indica orientação geral direcionada segundo $\mathrm{N} 30-60^{\circ} \mathrm{W}$, com mergulhos variáveis para NE e SW. 0 reconhecimento de uma variação sistemática nos mergulhos da foliação em escala regional e as observações de campo e dos estereogramas de contagem total de polos da foliação indicam que as dobras $\mathrm{F}_{3}$ mostram-se orientadas segundo a direção NW-SE. Essas dobras são normais com caimento, possuem formas abertas a fechadas e superfície axial aproximadamente vertical. As dobras $\mathrm{F}_{3}$ são assimétricas, com 0 flanco SW maior que o NE, influenciando nas concentrações dos polos da foliação dispostas nos estereogramas das figuras 12, 13 e 14. Os eixos das dobras $\mathrm{F}_{3}$ têm caimentos baixos (entre 15 e 25을 segundo as direções $\mathrm{N} 35^{\circ} \mathrm{W}$ e S50 $0^{\circ}$. Essa fase de dobramento controla a estruturação do relevo regional.

Uma fase de dobramentos mais tardia gerou as dobras $\mathrm{F}_{4}$, ocasionando uma variação da atitude média da foliação, entre $\mathrm{N} 35^{\circ} \mathrm{W}$ e $\mathrm{N} 75^{\circ} \mathrm{E}$ e afetando a orientação dos eixos das dobras $\mathrm{F}_{3}$. As dobras $\mathrm{F}_{4}$ possuem superfícies axiais variáveis direcionadas para $\mathrm{N} 30-80^{\circ} \mathrm{E}$, e têm eixos com caimentos de $55^{\circ}$ para $S 45^{\circ} \mathrm{W}$ e $52^{\circ}$ para $\mathrm{N} 75^{\circ} \mathrm{E}, \mathrm{e}$, subordinadamente, de $43^{\circ}$ para $\mathrm{N} 70^{\circ} \mathrm{E}$.

No estereograma de equiárea do setor norte contendo os polos da foliação principal é possível observar-se uma guirlanda de polos, configurando a forma geral das dobras $\mathrm{F}_{3}$, cujos eixos estão situados nos quadrantes NW-SE, $\left(320^{\circ}-145^{\circ}\right)$ (Fig. 12). As dobras $\mathrm{F}_{4}$ também podem ser observadas pela formação de uma guirlanda de polos, cujos eixos estão direcionados segundo N50$-60^{\circ} \mathrm{E}$ e $\mathrm{S} 50-60^{\circ} \mathrm{W}$, com caimento de $60^{\circ}$ e $40^{\circ}$. A atitude média da foliação metamórfica nesse setor é $\mathrm{N} 25^{\circ} \mathrm{W}$, com mergulho de $33^{\circ}$ para SW. A lineação mineral dos paragnaisses nesse setor está marcada pela orientação da biotita e da silimanita e tem caimento de $6^{\circ}$ para a direção S25 ${ }^{\circ}$ e $2^{\circ}$ para N $25^{\circ} \mathrm{W}$ (Fig. 12).

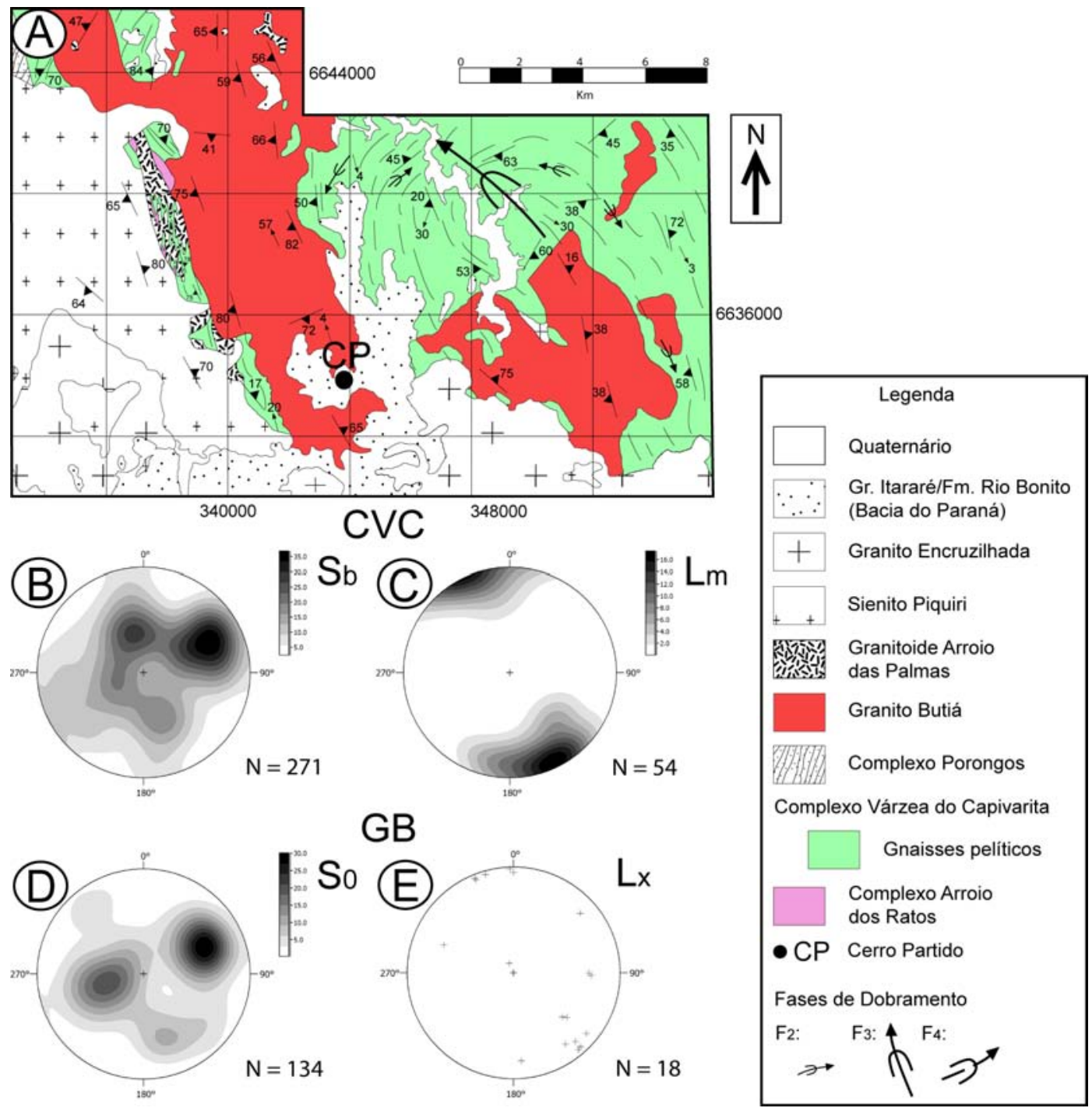

Figura 12. Mapa do setor norte da área destacando as estruturas das rochas e estereogramas representativos dos gnaisses pelíticos e leucogranitos peraluminosos. A) Mapa de superfície de forma dos gnaisses pelíticos com indicação das principais estruturas das rochas; B) Estereograma de contagem de polos do bandamento dos gnaisses; C) Estereograma de contagem de polos da lineação mineral dos gnaisses; D) Estereograma de contagem de polos da foliação ígnea dos leucogranitos; E) Estereograma de polos da lineação de estiramento dos leucogranitos. $\mathrm{CVC}=$ Complexo Várzea do Capivarita, GB=Granito Butiá. 
Nos estereogramas de contagem de polos do setor nordeste observa-se que a atitude da foliação principal nesse setor tem direção média $\mathrm{N} 25^{\circ} \mathrm{W}$ com mergulho de $50^{\circ}$ para SW (Fig. 13). Ainda é possível observar uma guirlanda não muito bem definida, afetando a atitude dos polos da foliação, e configurando a dobra $\mathrm{F}_{4^{\prime}}$ que possui plano axial direcionado segundo ENE. Nesse mapa observa-se que a orientação da foliação metamórfica encontrada no Metanortosito Capivarita é a mesma do CVC.

Nos dados de representação dos polos da foliação principal obtidos no setor sul visualiza-se uma guirlanda de polos menos bem definida, mas ainda configurando a forma geral das dobras $\mathrm{F}_{3}$, cujos eixos estão situados nos quadrantes NW-SE (Fig. 14). A atitude média do bandamento nesse setor é $\mathrm{N} 45^{\circ} \mathrm{W}$, com mergulho de $50^{\circ}$ para SW. No mapa da figura 14 é possível observar dobras da fase $\mathrm{F}_{4}$, embora sua visualização não seja clara nos estereogramas. A lineação mineral dos paragnaisses no setor sul também está marcada pela orientação de biotita e silimanita, com ângulo de caimento de $9^{\circ}$ para a direção $\mathrm{N} 45^{\circ} \mathrm{W}$ e de $2^{\circ}$ para $S 44^{\circ} \mathrm{E}$ (Fig. 14).

A retirada dos efeitos das dobras $\mathrm{F}_{3}$ revela a atitude média da foliação segundo a direção NW-SE com baixo angulo de mergulho para SW. A relação entre a atitude média da foliação principal e a lineação mineral resulta em rake de valores baixos $\left(<15^{\circ}\right)$ a intermediários $\left(15\right.$ a $\left.30^{\circ}\right)$, indicando uma relação de lineação do tipo oblíqua a direcional. Essa relação pode sugerir a atuação de processos deformacionais associados a um sistema transpressivo (Sanderson \& Marchini, 1984; Tikoff \& Teyssier, 1994; Tikoff \& Grene, 1997).

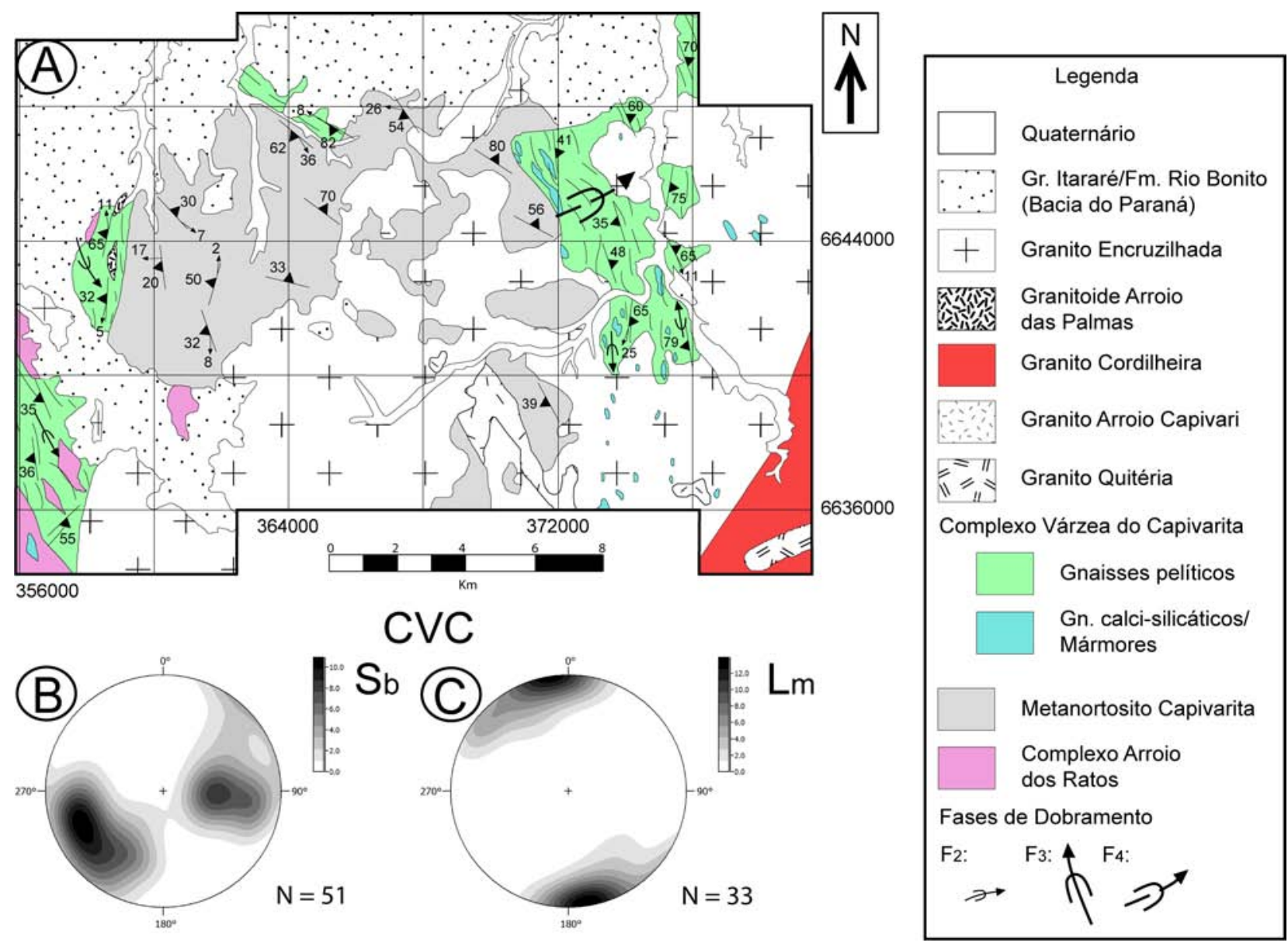

Figura 13. Mapa do setor nordeste da área destacando as estruturas das rochas e estereogramas representativos dos gnaisses pelíticos. A) Mapa de superfície de forma dos gnaisses pelíticos com indicação das principais estruturas das rochas; B) Estereograma de contagem de polos do bandamento dos gnaisses pelíticos; C) Estereograma de contagem de polos da lineação mineral dos gnaisses pelíticos. CVC=Complexo Várzea do Capivarita. 


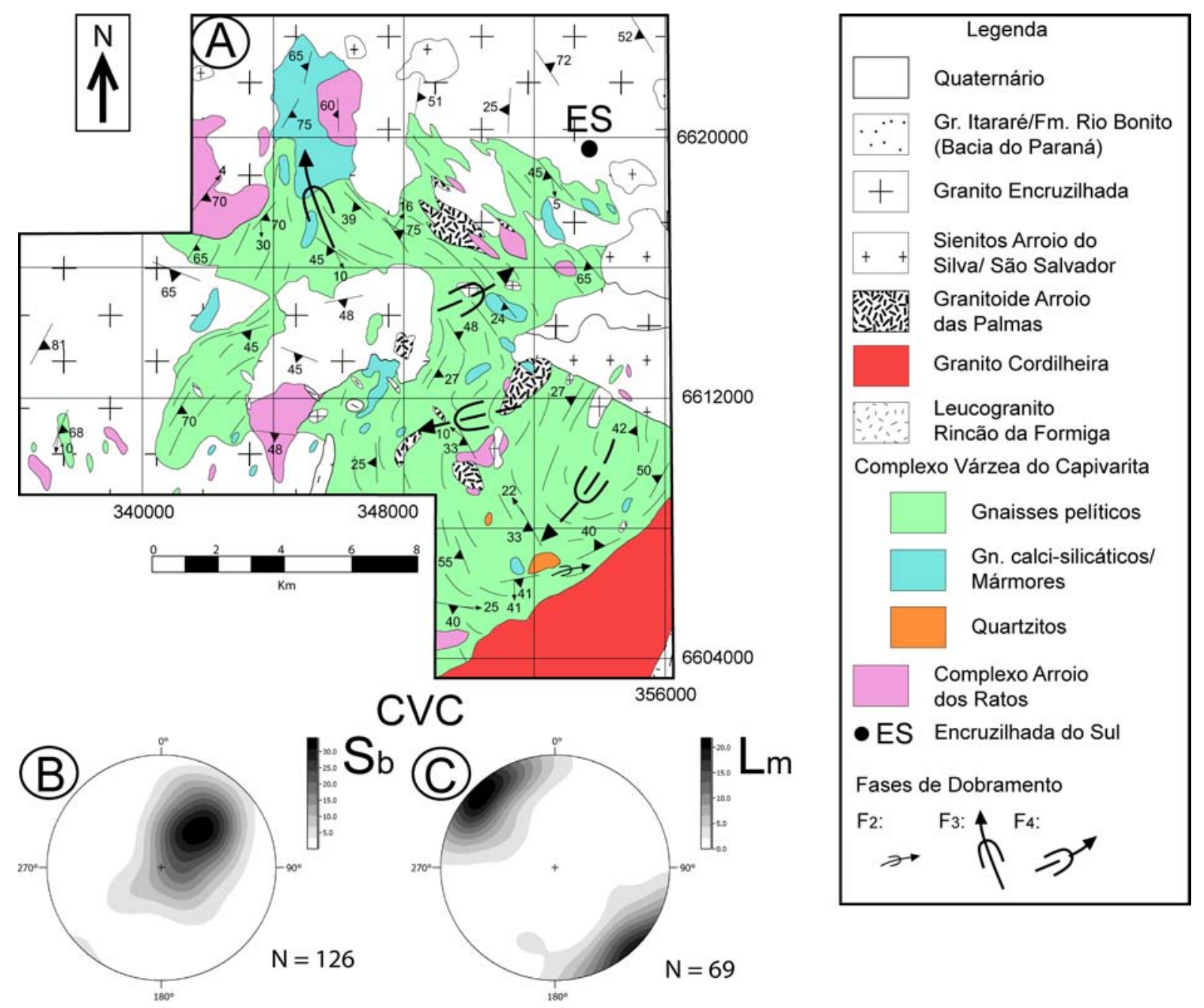

Figura 14. Mapa do setor sul da área destacando as estruturas das rochas e estereogramas representativos dos gnaisses pelíticos. A) Mapa de superfície de forma dos gnaisses pelíticos com indicação das principais estruturas das rochas; B) Estereograma de contagem de polos do bandamento dos gnaisses pelíticos; C) Estereograma de contagem de polos da lineação mineral dos gnaisses pelíticos. CVC=Complexo Várzea do Capivarita.

\section{Discussão}

\subsection{Condições metamórficas}

0 metamorfismo de alto grau das rochas da sequência pelítica produz um conjunto bem definido de minerais, caracterizados principalmente por aluminossilicatos como cianita e/ou silimanita, almandina, biotita, cordierita e ortopiroxênio, associados a quartzo, K-feldspato e plagioclásio. Em casos de temperaturas extremas ocorrem ainda espinélios e óxidos do tipo hercinita, safirina e coríndon, enquanto que as pressões mais elevadas ( $>10$ kbar) estão registradas pela ocorrência de granada acompanhada por cianita e rutilo (Yardley, 1989; Spear, 1993; Bucher \& Frey, 1994; Vernon \& Clarke, 2008; Bucher \& Grapes, 2011).

Nas condições metamórficas de ultra-alta temperatura (UAT ou UHT - ultra-high temperature) a pressão de $\mathrm{H}_{2} \mathrm{O}$ é muito menor que a pressão litostática $\left(\mathrm{P}_{\mathrm{L}}\right)$ e sua efetividade está diretamente relacionada à ocorrência de reações de quebra de minerais hidratados como muscovita e biotita. As assembleias contendo cordierita são muito comuns em metamorfismo de alto grau de rochas pelíticas. A ampla variação composicional entre Mg-Cordierita e granadas do tipo almandina habilita essa paragênese para os cálculos de geotermometria. A reação em equilíbrio das paragêneses cordierita-silimanita-granada e hercinita-quartzo define essa associação como excelente geobarômetro (Spear, 1993; Vernon \& Clarke, 2008; Bucher \& Grapes, 2011).

As principais reações químicas que ocorreram nos gnaisses pelíticos do CVC durante o pico de metamorfismo, foram identificadas por Gross et al. (2006): (a) $\mathrm{Bt}+\mathrm{Sil}+\mathrm{Qtz}=\mathrm{Grt}+\mathrm{Crd}+\mathrm{Kfs}+\mathrm{L}$; (b) Grt $+\mathrm{Bt}+\mathrm{Qtz}=$ $\mathrm{Opx}+\mathrm{Crd}+\mathrm{Kfs}+\mathrm{L} \mathrm{e} \mathrm{(c)} \mathrm{Bt}+\mathrm{Sil}=\mathrm{Grt}+\mathrm{Crd}+\mathrm{Kfs}+\mathrm{Spl}$ $+\mathrm{Mag}+\mathrm{Ilm}+\mathrm{L}$, onde Bt = biotita, $\mathrm{Sil}=$ silimanita, $\mathrm{Qtz}=$ quartzo, Grt = granada almandina, $\mathrm{Crd}=$ cordierita, $\mathrm{Kfs}$ = K-feldspato, $\mathrm{Opx}=$ ortopiroxênio, $\mathrm{Spl}=$ espinélio tipo hercinita, Mag = magnetita, $\mathrm{Ilm}=$ ilmenita e L = fusão.

Estudos mais recentes associados com trabalhos de mapeamento geológico em escala 1:25.000 desenvolvidos pelos alunos e professores das disciplinas de Mapeamento Geológico I e II do curso de Geologia da UFRGS (UFRGS, 2008; 2009; 2010; 2011) têm descrito paragêneses semelhantes às observadas anteriormente nos estudos de Frantz et al. (1984), Silva et al. (2002) e Gross et al. (2006). Entretanto, a observação detalha- 
da das paragêneses e das microestruturas nos gnaisses pelíticos e nas injeções leucograníticas tem indicado que as condições de metamorfismo são um pouco distintas daquelas sugeridas anteriormente.

Uma das principais reações metamórficas que marcam a evolução do metamorfismo do Complexo Várzea do Capivarita é: Grt+Crd+Sil=Hc+Qtz (Fig. 11). Essa reação permanece estável em condições de tem- peratura entre 900 e $1100^{\circ} \mathrm{C}$ e de pressão litostática entre 4 e 9 kbar (Fig. 15). Investigações recentes que levam em consideração a variação composicional dos minerais no sistema FMASH também mostram que a paragênese Grt+Crd+Sil é estável para uma temperatura fixa de $860^{\circ} \mathrm{C}$ em condições de pressão variável entre 4 e 8 kbar (Bucher \& Grapes, 2011).

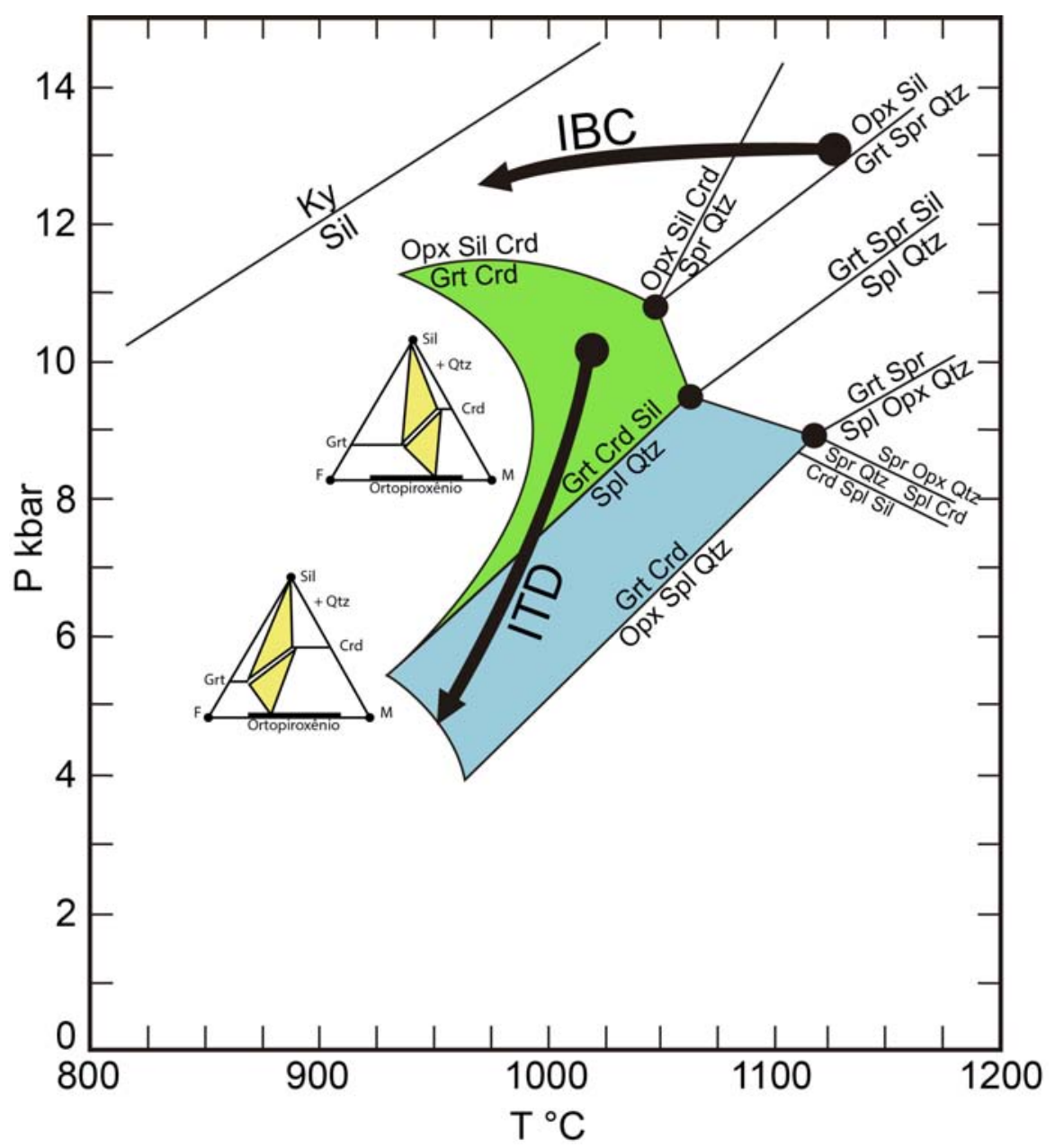

Figura 15. Diagrama P-T para rochas pelíticas mostrando os campos das paragêneses e as condições de equilíbrio das reações envolvendo granada, cordierita, silimanita e hercinita, bem como as trajetórias IBC (isobaric cooling) e ITD (isothermal descompression). (Spear, 1993).

Philipp \& Camozzato (2009) e Philipp et al. (2013) têm interpretado as paragêneses com Grt-Crd-Sil-HcBt-Qtz como associadas a condições gerais de temperatura entre 850 e $1000^{\circ} \mathrm{C}$ e condições de pressão intermediárias (entre 4 e 9 kbar). Os estudos de geotermobarometria por pseudoseção apresentados por esses autores indicam que o início da formação das fusões leucograníticas que geraram os corpos graníticos peraluminosos da Suíte Cordilheira ocorreram sob temperaturas entre 750 e $840^{\circ} \mathrm{C}$ e pressões da ordem de 8 a 9 kbar. Essas evidências permitem caracterizar essas condições de temperatura como sendo de alto grau e compatíveis com as da fácies granulito de ultra-alta temperatura (UHT).

A ocorrência da reação de formação da hercinita sugere que a evolução do metamorfismo do CVC foi caracterizada por um evento metamórfico principal que atingiu condições de pressão mais elevada e evoluiu posteriormente para condições de pressão mais baixa por soerguimento do sistema. Essa trajetória é atribuída a um padrão do tipo ITD (isothermal decompression) como sugerida por Spear (1993) (Fig. 15). Esse padrão é observado em cinturões orogênicos colisionais, sendo interpretado como resultado de um período de soerguimento associado ao colapso do cinturão após o ápice do espessamento.

\subsection{Migmatização e formação de leucogranitos}

A formação de granitos do tipo S (Chappell \& White, 1974), especificamente do tipo CPG (Cordierite-bearing peraluminous leucogranite; Barbarin, 1999), contendo cordierita magmática, é atribuída a fusão crustal de protólitos de composição pelítica (Barbarin, 1999). 
Esses processos formam corpos tabulares e microplútons com espessuras da ordem de 10 a 50 metros ou muito maiores (Vernon \& Clarke, 2008). Granitos peraluminosos com cordierita e granada ocorrem nas seções dos migmatitos de Inzie Head, na porção nordeste da Escócia (Johnson et al., 2001).

A relação entre os grandes corpos graníticos peraluminosos que se formam em níveis crustais superiores e os migmatitos que ocorrem na crosta inferior é de difícil comprovação. Existem dúvidas sobre o processo de acumulação, segregação e ascensão dos magmas e sobre seu transporte por diques para níveis crustais superiores. Ao mesmo tempo muitos granitos mostram evidências de mistura com magmas máficos e, portanto, fontes mantélicas. Ainda observa-se que as fusões geradas nos migmatitos são pobres em minerais máficos, enquanto que alguns granitos peraluminosos possuem altas proporções de minerais máficos (Vernon \& Clarke, 2008).

Entretanto, a ocorrência de granulitos residuais anidros ou fracamente hidratados com poucas injeções de fusão sugere que em determinadas condições, a fusão pode migrar da sua fonte, na crosta inferior, para se posicionar como um granito na crosta superior/ intermediária, deixando restitos granulíticos (Patiño-Douce, 1999; Brown, 2001; Guerina \& Sawyer, 2003; Brown, 2007; Vernon \& Clarke, 2008).

Em muitos cinturões colisionais ocorrem leucogranitos peraluminosos com muscovita e/ou biotita com mais de $70 \%$ de $\mathrm{SiO}_{2}$ e sem contribuição de magmatismo máfico. Esses granitos são interpretados como produto da fusão crustal de rochas metassedimentares de composição pelítica e/ou quartzo-feldspática (Patiño-Douce, 1999). A formação desses granitos é atribuída à fusão parcial sub-saturada em $\mathrm{H}_{2} \mathrm{O}$ durante a descompressão causada pelo colapso do cinturão orogênico, representando crosta continental espessada (Spear, 1993; Harris \& Massey, 1994; Patiño-Douce, 1999).

As fontes de calor prováveis para a geração de fusões crustais relacionadas por Vernon \& Clarke (2008) são: (1) descompressão da crosta espessada em cinturões orogênicos, gerando os clássicos leucogranitos colisionais; (2) ascensão da astenosfera abaixo da crosta em orógenos extensionais; (3) underplating maciço pela intrusão de magmas máficos mantélicos na base da crosta inferior; (4) ultrametamorfismo associado ao aumento da temperatura relacionado a gradientes geotérmicos da base da crosta em cinturões orogênicos colisionais. A geração da migmatização dos gnaisses do Complexo Várzea do Capivarita parece ter evoluído a partir da contribuição dos processos descritos nos itens 1,4 e, subordinadamente, no item 3, como sugerido pelos estudos de Philipp et al. (2013).

Thompson (1999) mostra que a geração de granitos envolvendo alto grau de fusão parcial requer grandes volumes de crosta pré-aquecidos pelo metamorfismo regional e amplo acesso a magmas externos derivados do manto, tais como os que podem ser gerados por delaminação da raiz dos cinturões orogênicos associados aos processos de slab break-off (Davies \& Von Blanckenburg, 1995, 1998).

Dados de campo, petrográficos e experimentais indicam que a maioria das reações de formação de fusões em rochas crustais ocorrem sob condições de P-T da fácies granulito $\left(800-1000^{\circ} \mathrm{C}\right)$ e sem $\mathrm{H}_{2} \mathrm{O}$ disponível (Wyllie et al., 1976; Wyllie, 1977; Thompson, 1982; Clemens \& Watkins, 2001; Clemens, 2005ab). Essas reações são chamadas de Dehydration Melting Reactions (Thompson, 1982) e Vapor-Absent Melting Reactions (Grant, 1985). A fonte de $\mathrm{H}_{2} \mathrm{O}$ para a fusão parcial dos metapelitos é oriunda da desidratação de minerais hidratados como muscovita e biotita. Uma das principais reações de fusão é a da quebra da muscovita $(\mathrm{Ms}+\mathrm{Pl}+$ $\mathrm{Qtz}=\mathrm{Als}+\mathrm{Kfs}+\mathrm{L}$ ), que ocorre a partir da fácies anfibolito médio e gera fusões ricas em Kfs. Essa reação, apesar de muito importante, gera líquidos em condições muito próximas da linha solidus e, dessa maneira, não podem ascender para níveis crustais mais rasos (Vernon \& Clarke, 2008).

De outro modo, as reações envolvendo a quebra da biotita $(\mathrm{Bt}+\mathrm{Als}+\mathrm{Qtz}=\mathrm{Grt} / \mathrm{Crd}+\mathrm{Kfs}+\mathrm{L} \mathrm{e} \mathrm{Bt}+\mathrm{Pl}+$ $\mathrm{Als}+\mathrm{Qtz}=\mathrm{Grt} / \mathrm{Crd}+\mathrm{Kfs}+\mathrm{L}$ ) ocorrem sob condições de alto grau para pelitos contendo ou não plagioclásio, e sob condições de pressão intermediária, quando sucedem em presença de granada e cordierita. Essas fusões acontecem sob condições de temperatura mais elevada e, dessa forma, posicionam-se mais afastadas da linha solidus, favorecendo a movimentação dos líquidos gerados para níveis crustais mais rasos (Vernon \& Clarke, 2008). Os dados observados nos gnaisses pelíticos do Complexo Várzea do Capivarita são sugestivos de amplo processo de migmatização associado a quebra da biotita.

\section{Conclusões}

Os neossomas e/ou leucossomas contendo uma mineralogia a base de Kfs+Qtz e ricos em Grt e/ou Crd são bons indicadores da ocorrência de fusão parcial sub-saturada em $\mathrm{H}_{2} \mathrm{O}$, gerada a partir da reação de quebra da biotita (Tracy \& Robinson, 1983; Waters \& Whales, 1984; Waters, 1988; Powell \& Downes, 1990; Vernon et al., 1990, 2003; White et al., 2004; Vernon \& Clarke, 2008). Após a separação da fase fundida félsica e hidratada dos produtos sólidos das reações desidratadas, produz-se um resíduo de granulitos "secos" (restito), que são empobrecidos nos componentes félsicos da fusão.

Os estudos experimentais indicam que as reações de quebra da biotita representam as reações de fusão parcial mais comuns para metapelitos e componentes félsicos na porção intermediária e profunda da crosta (Holdaway \& Lee, 1977; Clemens \& Wall, 1981; Thompson, 1982; Tracy \& Robinson, 1983; Grant, 1985; Waters, 1988; Vielzeuf \& Holloway, 1988; Patiño-Douce 
\& Johnston, 1991; Stevens et al., 1997; Johnson et al., 2001).

Os magmas produzidos por essas reações podem se conectar por segregação e gerar granitos peraluminosos (tipo S) em níveis crustais rasos se tiverem acesso a estruturas subverticais como zonas de cisalhamento ou zonas de falhas de extensão, que possibilitam a rápida ascensão e posicionamento das fusões (Clemens \& Wall, 1981).

As fusões geradas pela quebra da muscovita e sem presença de $\mathrm{H}_{2} \mathrm{O}$ livre têm variação positiva de volume, resultando no aumento da pressão de fluidos, promovendo o fraturamento adjacente aos grãos minerais e o escapamento da fusão associada à diminuição da pressão e da temperatura (Connolly et al. 1997; Rushmer, 2001). Nessas condições as fusões perdem calor rapidamente e cristalizam na própria zona de geração da fusão.

Por outro lado, as fusões geradas pela quebra da biotita e sem presença de $\mathrm{H}_{2} \mathrm{O}$ livre envolvem apenas pequena variação positiva de volume ou até mesmo negativa, resultando que a fusão pode permanecer no local da fusão ou pode migrar, principalmente, se for associada a estruturas tectônicas como zonas de cisalhamento (Rushmer, 2001; Holyoke \& Rushmer, 2002). As várias reações de fusão podem ocorrer durante a evolução do metamorfismo progressivo, com cada sucessivo episódio ocorrendo em altas temperaturas e sob baixa atividade de $\mathrm{H}_{2} \mathrm{O}$, produzindo fusões com diferentes composições químicas (Powell, 1983; Sawyer, 1998).

As evidências petrográficas e de geotermobarometria sugerem que o Complexo Várzea do Capivarita foi submetido a condições metamórficas máximas de ultra-alta temperatura (UAT), sob temperaturas acima de $900^{\circ} \mathrm{C}$ e pressões entre 6 e 10 kbar (Philipp et al., 2013). Isso possibilitou a fusão parcial dos gnaisses pelíticos sub-saturados em água a partir de processos de dehydration melting gerados a partir da quebra da biotita. As condições metamórficas extremas registradas no CVC são sugestivas de um episódio significativo de fusão parcial sob ausência de fluidos (fluid-absent melting), que pode ter gerado volumes elevados de magmas. Estudos recentes têm demonstrado que esse tipo de fusão pode produzir entre $20-35 \%$ de fusão em metapelitos (Clemens \& Vielzeuf, 1987; Sawyer, 1996). As evidências petrográficas e os estudos de geotermobarometria por pseudoseção levaram Philipp \& Camozzato (2009) e Philipp et al. (2013) a sugerir que a fusão dos gnaisses metapelíticos do CVC foi responsável pela geração de grande volume de líquidos graníticos que foram segregados e ascenderam ao longo da Zona de Cisalhamento Dorsal de Canguçu para constituir os corpos graníticos peraluminosos da Suíte Cordilheira.

Os trabalhos de Chemale Jr. (2000), Saalmann et al. (2007) e Hartmann et al. (2007) apresentaram análises integradas dos dados disponíveis para as principais unidades geotectônicas do Escudo Sul-rio-grandense.
Hartmann et al. (2007) identificaram dois eventos colisionais; o primeiro, está associado à Orogênese São Gabriel (860-680 Ma), relacionada ao início do Ciclo Orogênico Brasiliano e está registrado nas unidades do Terreno São Gabriel. 0 segundo evento colisional está relacionado à Orogênese Dom Feliciano (650-550 Ma), que ocorreu no final da referida orogenia. As idades desse evento de metamorfismo orogênico, entre 650 e $620 \mathrm{Ma}$, foram registradas nas idades $\mathrm{U}-\mathrm{Pb}$ em zircão nos complexos Encantadas e Porongos, no Metanortosito Capivarita e no próprio CVC (Gruber et al., 2010; Chemale Jr. et al., 2011; Bom, 2011; Bom et al., 2012; Camozzato et al., 2013).

0 primeiro evento colisional Brasiliano correspondeu a um sistema inicial de empurrões oblíquos que evoluíram para um conjunto de zonas de cisalhamento transcorrentes de alto ângulo, cuja evolução final ocorreu provavelmente entre 710-700 Ma (Hartmann et al., 2007, 2011). Os eventos de deformação mais tardios estão registrados em todas as unidades geotectônicas do Cinturão Dom Feliciano e marcam episódios relacionados à segunda colisão do Ciclo Orogênico Brasiliano, representando a evolução de um sistema de zonas de cisalhamento dúcteis, oblíquas a transcorrentes, ocorridas entre 650 e $600 \mathrm{Ma}$ (Chemale Jr. et al., 2011; Philipp et al., 2013; Camozzato et al., 2013). 0 último evento deformacional está registrado em todas as unidades e se caracteriza pelo colapso gravitacional do Cinturão Dom Feliciano, com a abertura da Bacia do Camaquã ao redor de $600 \mathrm{Ma}$, finalizando com a deposição dos sedimentos da Formação Guaritas, em 540 Ma.

Na região de Quitéria e Encruzilhada do Sul foram descritos diversos episódios de geração de magmatismo granítico, representado pelo Granito Quitéria e pelos granitos peraluminosos da Suíte Cordilheira (Koester, 1995; Nardi \& Frantz, 1995; Koester et al., 2001; Frantz et al., 2003). Philipp \& Camozzato (2009) e Camozzato et al. (2012) descrevem a ocorrência de granitos peraluminosos correlatos à Suíte Cordilheira, intrusivos no Complexo Porongos. 0 posicionamento desses corpos está associado à segunda fase de deformação e metamorfismo que afetou esse complexo. Mais recentemente, Philipp et al. (2013) propõem, a partir de novos dados estruturais e geotermobarométricos, a adaptação do modelo de geração desse magmatismo apresentado anteriormente por Koester (1995) e Koester et al. (2001). Nesse modelo a geração dos granitos da Suíte Cordilheira está relacionada à fusão parcial dos gnaisses pelíticos do CVC durante o segundo episódio de metamorfismo regional colisional que teria ocorrido entre 630 e 620 Ma (Chemale Jr. et al., 2011; Bom, 2011; Bom et al., 2012). Os autores ainda ressaltam que as condições metamórficas atingiram temperaturas entre 850 e $1000^{\circ} \mathrm{C}$ e pressões da ordem de 6 a 10 kbar. Essas condições indicam que esse evento metamórfico atingiu condições de ultra-alta temperatura (UAT), gerando o magmatismo peraluminoso a partir de fusões parciais incongruentes (incongruent melting) 
derivados de reações envolvendo a quebra da biotita (Philipp et al., 2009, 2013).

\section{Considerações finais}

Os dados apresentados e disponíveis na bibliografia (Gross et al., 2006; Philipp et al., 2009, 2013) possibilitaram a caracterização do metamorfismo que atuou sobre o Complexo Várzea do Capivarita e de um episódio magmático intrusivo correlato e contemporâneo ao evento metamórfico datado (Bom, 2011; Bom et al., 2012). As injeções graníticas existentes nos gnaisses pelíticos do Complexo Várzea do Capivarita são fusões parciais do mesmo. Ao se unirem, as pequenas injeções deram origem a corpos de leucogranitos de espessuras métricas, e provavelmente ao Granito Butiá. Esses corpos se posicionaram provavelmente na crosta inferior.

A relação entre a atitude média da foliação principal e a lineação mineral observadas no Complexo Várzea do Capivarita, retirando-se os efeitos da fase de dobramento $\mathrm{F}_{3}$, sugere cinemática com movimentação do tipo oblíqua resultante da atuação de processos deformacionais associados a sistema transpressivo.

As condições metamórficas estabelecidas com base nas paragêneses identificadas permitem estimar temperaturas da ordem de 850 a $1000^{\circ} \mathrm{C}$ e pressões entre 6 e $10 \mathrm{kbar}$, caracterizando o metamorfismo como da série de pressão intermediária e ultra-alta temperatura (UAT). As relações espaciais entre as paragêneses encontradas nos gnaisses pelíticos indicam que a trajetória desenvolvida pelos gnaisses do Complexo Várzea do Capivarita é compatível com padrão tipo ITD (isothermal decompression). Esse tipo de trajetória é desenvolvido em cinturões metamórficos gerados em eventos colisionais.

Trabalhos futuros terão como objetivo melhor entendimento da proveniência sedimentar e da idade de cristalização metamórfica dos gnaisses pelíticos e dos granitos peraluminosos associados.

\section{Referências}

Almeida, F.F.M. 1977. O Cráton do São Francisco. Revista Brasileira de Geociências, 7(4): 349-364.

Almeida, F.F.M., Hasui, Y., Brito Neves, B.B. \& Fuck, R.A. 1981. Brazilian structural provinces: an introduction. Earth Sciences Reviews, 17: 1-21.

Babinski, M., Chemale Jr., F., Van Schmus, W.R., Hartmann, L.A. \& Silva, L.C. 1996. U-Pb and Sm-Nd geochronology of the Neoproterozoic granitic-gneissic Dom Feliciano belt, southern Brazil. Journal of South American Earth Sciences, 10 (3-4): 263-274.

Barbarin, B. 1999. A review of the relationships between granitoid types, their origins and their geodynamic environments. Lithos, 46: 605-626

Bitencourt, M.F. \& Nardi, L.V.S. 2000. Tectonic setting and sources of magmatism related to the southern Brazilian shear belt. Revista Brasileira de Geociências, 30: 184-187

Bom, F.M. 2011. Origem e Evolução do Complexo Várzea do Capivarita, Encruzilhada do Sul, RS. Porto Alegre, 73p.
Monografia de Conclusão de Curso, Curso de Geologia, Instituto de Geociências, Universidade Federal do Rio Grande do Sul.

Bom, F.M., Philipp, R.P. \& Pimentel, M.M. 2012. Idade U-Pb SHRIMP do metamorfismo do Complexo Várzea do Capivarita e de geração de leucogranitos peraluminosos, Cinturão Dom Feliciano, Encruzilhada do Sul - RS. In: CONGRESSO BRASILEIRO DE GEOLOGIA, 46, 2012, Santos. Anais... Santos, SBG.

Brown, M. 2001. Orogeny, migmatites and leucogranites: A review. Proceeding of the Indian Academy of Sciences (Earth and Planetary Sciences), 110: 316-336.

Brown, M. 2007. Crustal melting and melt extraction, ascent and emplacement in orogens: mechanisms and consequences. Journal of the Geological Society of London, 164: 709-730.

Bucher, K. \& Frey, M. 1994. Petrogenesis of Metamorphic Rocks. Berlin, Heidelberg, Springer-Verlag, 315p.

Bucher, K. \& Grapes, R. 2011. Petrogenesis of Metamorphic Rocks. Berlin, Heidelberg, Springer-Verlag, 428p.

Camozzato, E., Lopes, R.C., Philipp, R.P. \& Klein, C. 2012. Geologia e Recursos Minerais da Folha Hulha Negra (SH.22-Y-C-I), Programa de Levantamentos geológicos Básicos, CPRM, Porto Alegre, $214 \mathrm{p}$.

Camozzato, E., Philipp, R.P. \& Chemale Jr., F. 2013. Evolução tectônica e geocronologia U-Pb em zircão da terminação sul do Terreno Tijucas (RS, Brasil). In: CONGRESO URUGUAYO DE GEOLOGÍA, 13, SIMPOSIO DE MINERÍA Y DESARROLLO DEL CONO SUR, 1, 2013, Montevideo. Resumos Expandidos.

Chappell, B.W. \& White, A.J.R. 1974. Two contrasting granite types. Pacific Geology, 8: 173-174.

Chemale Jr., F. 2000. Evolução geológica do Escudo Sul-rio-grandense. In: Holz, M. \& De Ros, L.F. (Eds.). Geologia do Rio Grande do Sul. Porto Alegre, Editora da UFRGS, p. 1352.

Chemale Jr., F., Philipp, R.P., Dussin, I., Formoso, M.L.L., Kawashita, K. \& Berttotti, A.L. 2011. Lu-Hf and U-Pb age determination of the Capivarita Anorthosite, Dom Feliciano Belt, Brazil. Precambrian Research, 186: 117-126.

Clemens, J.D. 2005a. Granites and granitic magmas: strange phenomena and new perspective on old problems. Proceedings of the Geologists' Association, 116: 9-16.

Clemens, J.D. 2005b. Rejoinder to 'Granite and granitic magmas'. Proceedings of the Geologists' Association, 116: 2529.

Clemens, J.D. \& Vielzeuf, D. 1987. Constraints on melting and magma production in the crust. Earth and Planetary Science Letters, 86: 287-306.

Clemens, J.D. \& Wall, V.J. 1981. Origin and crystallization of some peraluminous (S-type) granitic magmas. Canadian Mineralogist, 19: 111-131.

Clemens, J.D. \& Watkins, J.M. 2001. The fluid regime of high-temperature metamorphism during granitoid magma genesis. Contributions to Mineralogy and Petrology, 140: 600-606.

Connolly, J.A.D., Holness, M.B., Rubie, D.C. \& Rushmer, T. 1997. Reaction-induced microcracking: an experimental investigation of a mechanism for enhancing anatectic melt extraction. Geology, 25: 591-594.

Davies, J.H. \& Von Blanckenburg, F. 1995. Slab breakoff: a model lithosphere detachment and its test in the magmatism and deformation of collisional orogens. Earth and Planetary Science Letters, 129: 85-102. 
Davies, J.H. \& Von Blanckenburg, F. 1998. Thermal controls on slab breakoff and the rise of high-pressure rocks during continental collisions. In: Hacker, B.R. \& Liou, J.G. (Eds.). When Continents Collide: Geodynamics and Geochemistry of Ultra-High Pressure Rocks. Netherlands, Kluwer Academic Publishers, 97-115.

Fernandes, L.A.D., Tommasi, A. \& Porcher, C.C. 1992. Deformation patterns in the southern Brazilian branch of the Dom Feliciano Belt: A reappraisal. Journal of South American Earth Science, 5: 77-96.

Fernandes, L.A.D., Tommasi, A., Porcher, C.C., Vieira Jr., N., Marques-Toigo, M., Guerra-Sommer \& Piccoli, A.E. 1988. Mapa geológico de parte das folhas de Quitéria (SH 22-Y-B-I-4) e Várzea do Capivarita (SH 22-Y-B-I-3), RS. Porto Alegre, 1 mapa preto e branco, escala 1:50.000. Série Mapas, Instituto de Geociências, Universidade Federal do Rio Grande do Sul.

Fragoso-Cesar, A.R.S. 1980. O Cráton de Rio de la Plata e o Cinturão Dom Feliciano no Escudo Uruguaio-Sul-rio-grandense. In: CONGRESSO BRASILEIRO DE GEOLOGIA, 31, 1980, Camboriú. Anais... Camboriú, SBG, v.5, p. 28792892.

Fragoso-Cesar, A.R.S. 1991. Tectônica de Placas no Ciclo Brasiliano: As Orogenias dos Cinturões Dom Feliciano e Ribeira no Rio Grande do Sul. São Paulo, 367p. Tese de Doutorado, Curso de Pós-Graduação em Geociências, Instituto de Geociências, Universidade de São Paulo.

Frantz, J.C., Lima, E.F., Machado, R.P. \& Naumann, M. 1984. Contribuição à geologia de Encruzilhada do Sul - RS. In: CONGRESSO BRASILEIRO DE GEOLOGIA, 33, 1984, Rio de Janeiro. Anais... Rio de Janeiro, SBG, v.5, p. 2407-2416.

Frantz, J.C., McNaughton, N.J., Marques, J.C., Hartmann, L.A., Botelho, N.F. \& Caravaca, G. 2003. SHRIMP U-Pb zircon ages of granitoids from southernmost Brazil: constrains on the temporal evolution of the Dorsal de Canguçu Transcurrent Shear Zone and Eastern Dom Feliciano Belt. In: SOUTH AMERICAN SYMPOSIUM ON ISOTOPE GEOLOGY, 4, 2003, Salvador. Short Papers...Salvador, SBG, v. 1, p. $174-177$.

Grant, J.A. 1985. Phase equilibria in partial melting of pelitic rocks. In: Ashworth, J.A. (Ed.). Migmatites. Glasgow, Blackie, p. 86-144.

Gross, A.O.M.S, Porcher, C.C., Fernandes, L.A.D. \& Koester, E. 2006. Neoproterozoic low-pressure/high-temperature colisional metamorphic evolution in the Varzea do Capivarita Metamorphic Suite, SE Brazil: Thermobarometric and Sm/Nd evidence. Precambrian Research, 147: 41-64.

Gruber, L. 2010. Geocronologia U-Pb em Zircão Detrítico aplicada ao estudo de proveniência de metassedimentos do Complexo Metamórfico Porongos - Região de Santana da Boa Vista, RS. Porto Alegre, 131p. Dissertação de Mestrado, Programa de Pós-Graduação em Geociências, Instituto de Geociências, Universidade Federal do Rio Grande do Sul.

Guerina, S. \& Sawyer, E.W. 2003. Large-scale melt-depletion in granulite terranes: an example from the Archean Ashuanipi Subprovince of Quebec. Journal of Metamorphic Geology, 21: 181-201.

Harris, N.B.W. \& Massey, J. 1994. Decompression and anatexis of the Himalayan metapelites. Tectonics, 13: 1537-1546.

Hartmann, L.A., Chemale Jr., F. \& Philipp, R.P. 2007. Evolução geotectônica do Rio Grande do Sul no Pré-Cambriano. In: Ianuzzi, R. \& Frantz, J.C. (Eds.). 50 Anos de Geologia: Instituto de Geociências. Contribuições. Porto Alegre, Editora
Comunicação e Identidade, p. 97-123.

Hartmann, L.A., Philipp, R.P., Santos, J.O.S. \& McNaughton, N.J. 2011. Time frame of 753-680 Ma juvenile accretion during the São Gabriel orogeny, southern Brazil. Gondwana Research, 19: 84-99.

Heilbron, M., Pedrosa-Soares, A.C., Silva, L.C., Campos Neto, M.C. \& Trouw, R.A.J. 2004. Província Mantiqueira. In: Mantesso-Neto, V., Bartorelli, A., Carneiro, C.D.R. \& Brito Neves, B.B. (Eds.). Geologia do Continente Sul-Americano: Evolução da Obra de Fernando Flávio Marques de Almeida. São Paulo, Beca, p. 203-234.

Holdaway, M.J. \& Lee, S.M. 1977. Fe-Mg cordierite stability in high-grade pelitic rocks based on experimental, theoretical and natural observations. Contributions to Mineralogy and Petrology, 63: 175-198.

Holyoke, C.W. \& Rushmer, T. 2002. An experimental study of grain scale melt segregation mechanisms in two common crustal rock types. Journal of Metamorphic Geology, 20: 493-512.

Johnson, T.E., Hudson, N.F.C. \& Droop, G.T.R. 2001. Partial melting in the Inzie Head gneisses: the role of water and a petrogenetic grid in KFSMASH applicable to anatectic pelitic migmatites. Journal of Metamorphic Geology, 19: 99-118.

Koester, E. 1995. Evolução geológica do magmatismo sintectônico à Zona de Cisalhamento Transcorrente Dorsal de Canguçu, Região de Encruzilhada do Sul, RS. Porto Alegre, 240p. Dissertação de Mestrado, Programa de Pós-Graduação em Geociências, Instituto de Geociências, Universidade Federal do Rio Grande do Sul.

Koester, E., Roisenberg, A., Fernandes, L.A.D., Soliani Jr., E., Nardi, L.V.S. \& Kraemer, G. 2001. Petrologia dos granitóides sintectônicos à Zona de Cisalhamento Transcorrente Dorsal de Canguçu, Encruzilhada do Sul, RS. Revista Brasileira de Geociências, 31(2): 131-140.

Martil, M.M.D. 2007. Relações de Intrusão do Maciço Sienítico Piquiri, RS, com Suas Encaixantes. Porto Alegre, 71p. Monografia de Conclusão de Curso, Curso de Geologia, Instituto de Geociências, Universidade Federal do Rio Grande do Sul.

Martil, M.M.D. 2010. Caracterização estrutural e petrológica do magmatismo pré-colisional do Escudo Sul-rio-grandense: os ortognaisses do Complexo Metamórfico Várzea do Capivarita. Porto Alegre, 77p. Dissertação de Mestrado, Programa de Pós-Graduação em Geociências, Instituto de Geociências, Universidade Federal do Rio Grande do Sul.

Martil, M.M.D., Bitencourt, M.F. \& Nardi, L.V.S. 2011. Caracterização estrutural e petrológica do magmatismo pré-colisional do Escudo Sul-rio-grandense: os ortognaisses do Complexo Metamórfico Várzea do Capivarita. Pesquisas em Geociências, 38(2): 181-201.

Nardi, L.V.S. \& Frantz, J.C. 1995. The Cordilheira Intrusive Suite: Late Proterozoic peraluminous granitoids from southern Brazil. Journal of South American Earth Sciences, 8(1): 55-63.

Niessing, M. 2008. Geology and stratigraphic definition of the Butiá Granite: a sillimanite-bearing syntectonic leucogranite from the Sul-rio-grandense Shield. Munique, 104p. Dissertação de Mestrado, Civil and Geodetic Engeneering, Technische Universität München.

Niessing, M., Bitencourt, M.F., Kruhl, J.H., Martil, M.M.D., Gregory, T.R., Centeno, A.P., Fontana, E. \& Knijnik, D.B. 2008. Geology and stratigraphic definition of the Butiá Granite: a sillimanite-bearing syntectonic leucogranite from the 
Sul-rio-grandense Shield. In: CONGRESSO BRASILEIRO DE GEOLOGIA, 44, Curitiba, 2008. Anais... Curitiba, SBG, p. 522. (CD-Rom).

Oyhantçabal, P.B., Siegesmund, S., Wemmer, K., Presnyakov, S. \& Layer, P. 2009. Geochronological constraints on the evolution of the southern Dom Felician Belt (Uruguay). Journal of the Geological Society of London, 166: 10751084.

Patiño-Douce, A.E. 1999. What do experiments tell us about the relative contributions of crust and mantle to the origin of granitic magmas? In: Castro, A., Fernandez, C. \& Vigneresse, J.E. (Eds.). Undestanding Granites: New and Classical Techniques. Geological Society of London Special Publications, 168: 55-75.

Patiño-Douce, A.E. \& Johnston, A.D. 1991. Phase equilibria and melt productivity in the pelitic system: implications for the origin of peraluminous granitoids and aluminous granulites. Contributions to Mineralogy and Petrology, 107: 202-218.

Philipp, R.P. \& Camozzato, E. 2009. A colocação do Batólito Pelotas e suas relações com o metamorfismo regional orogênico no cinturão Dom Feliciano, RS. In: SIMPÓSIO NACIONAL DE ESTUDOS TECTÔNICOS, 12, INTERNATIONAL SYMPOSIUM OF TECTONIC STUDIES, 6, 2009, Ouro Preto. Anais... Ouro Preto, SBG, p. 112.

Philipp, R.P. \& Machado, R. 2005. The Neoproterozoic to Cambrian Granitic Magmatism of Pelotas Batholith, Southern Brazil. Journal of South American Earth Science, 19: 461478.

Philipp, R.P., Machado, R. \& Chemale Jr, F. 2007. A geração dos granitóides Neoproterozóicos do Batólito Pelotas: evidências dos isótopos de $\mathrm{Sr}$ e $\mathrm{Nd}$ e implicações para o crescimento continental da porção sul do Brasil. In: Iannuzzi, R. \& Frantz. J.C. (Ed.). 50 anos de Geologia: Instituto de Geociências. Contribuições. Porto Alegre, Comunicação e Identidade, p. 59-77.

Philipp, R.P., Massonne, H.J. \& Campos, R. 2009. Peraluminous leucogranites of Cordilheira Suite: register of Neoproterozoic collision and generation of the Pelotas Batolith, Dom Feliciano Belt, southern Brazil. In: SIMPÓSIO NACIONAL DE ESTUDOS TECTÔNICOS, 12; INTERNATIONAL SYMPOSIUM OF TECTONIC STUDIES, 6, 2009, Ouro Preto. Anais... Ouro Preto, SBG, p. 110.

Philipp, R.P., Massonne, H-J \& Campos, R. 2013. Peraluminous leucogranites of the Cordilheira Suite: A record of Neoproterozoic collision and the generation of the Pelotas Batholith, Dom Feliciano Belt, Southern Brazil. Journal of South American Earth Sciences, 43: 8-24.

Philipp, R.P., Nardi, L.V.S. \& Bitencourt, M.F. 2000. O Batólito Pelotas no Rio Grande do Sul. In: Holz, M. \& De Ros, L.F. (Ed.). Geologia do Rio Grande do Sul. Porto Alegre, CIGO/ UFRGS, p.133-160.

Powell, R. 1983. Processes in granulite-facies metamorphism. In: Atherton, M.P. \& Gribble, C.D. (Eds.). Migmatites, Melting and Metamorphism. Nantwich, Shiva, p. 127-139.

Powell, R. \& Downes, J. 1990. Garnet porphyroblast-bearing leucosomes in metapelites: mechanisms and an example from Broken Hill, Australia. In: Ashworth, J.R. \& Brown, M. (Eds.). High Temperature Metamorphism and Crustal Anatexis. London, Unwin Hyman, p. 105-123.

Ribeiro, M. \& Fantinel, L.M. 1978. Associações petrotectônicas do Escudo Sul-rio-grandense: I - Tabulação e distribuição das associações petrotectônicas do Escudo do Rio Grande do Sul. Iheringia, Série Geológica, 5: 19-54.
Rushmer, T. 2001. Volume change during partial melting reactions: implications for melt extraction, melt geochemistry and crustal rheology. Tectonophysics, 342: 389-405.

Saalmann, K., Hartmann, L.A. \& Remus, M.V.D. 2007. The assembly of West Gondwana-The view from the Rio de la Plata craton. In: Linnemann, U., Nance, R.D., Kraft, P. \& Zulauf, G. (Eds.). The Evolution of the Rheic Ocean: From Avalonian-Cadomian Active Margin to Alleghenian-Variscan Collision. Geological Society of America Special Paper, 423: 1-26.

Sanderson D.J. \& Marchini W.R.D. 1984.Transpression. Journal of Structural Geology, 6: 449-458.

Sawyer, E.W. 1996. Melt segregation and magma flow in migmatites: implications for the generation of granite magmas. Transactions of the Royal Society of Edinburgh: Earth Sciences, 87: 85-94.

Sawyer, E.W. 1998. Formation and evolution of granite magmas during crustal reworking: the significance of diatexites. Journal of Petrology, 39: 1147-1167.

Silva, A.O.M., Porcher, C.C., Fernandes, L.A.D. \& Droop, G.T.R. 2002. Termobarometria da Suíte Metamórfica Várzea do Capivarita (RS): Embasamento do Cinturão Dom Feliciano. Revista Brasileira de Geociências, 32: 419-432.

Soliani Jr., E. 1986. Os dados geocronológicos do Escudo Sul-rio-grandense e suas implicações de ordem geotectônica. São Paulo, 425 p. Tese de Doutorado, Curso de Pós-Graduação em Geociências, Instituto de Geociências, Universidade de São Paulo.

Spear, F.S. 1993. Metamorphic Phase Equilibria and Pressure-Temperature-Time Paths. Washington, D.C., Mineralogical Society of America, 799p.

Stevens, G., Clemens, J.D. \& Droop, G.T.R. 1997. Melt production during granulite-facies anatexis: experimental data from "primitive" metasedimentary protoliths. Contributions to Mineralogy and Petrology, 128: 352-370.

Tikoff, B. \& Greene, D. 1997. Stretching lineations in transpressional shear zones: an example from the Sierra Nevada Batholith, California. Journal of Structural Geology, 19: 29-39.

Tikoff, B. \& Teyssier, C. 1994. Strain modeling of displacement-field partitioning in transpressional orogens. Journal of Structural Geology, 16: 1575-1588.

Thompson, A.B. 1982. Dehydration melting of pelitic rocks and the generation of $\mathrm{H}_{2} \mathrm{O}$ undersaturated granitic liquids. American Journal of Science, 282: 1567-1595.

Thompson, A.B. 1999. Some time-space relationship for crustal melting and granitic intrusion at various depths. In: Castro, A., Fernández, C. \& Vigneresse, J.-L. (Eds.). Understanding Granites: Integrating New and Classic Techniques. Geological Society of London Special Publication, 168: 7-25.

Tracy, R.J. \& Robinson, P. 1983. Acadian migmatite types in pelitic rocks of central Massachusetts. In: Atherton, M.P. \& Gribble, C.D. (Eds.). Migmatites, Melting and Metamorphism. Nantwich, Shiva, p. 163-173.

UFRGS. Universidade Federal do Rio Grande do Sul. 2008. Mapeamento Geológico 1:25 000 de parte das folhas Passo das Canas SH-22-Y-A-III-4 (MI2984/4) e Capané SH 22-Y-A-III-3 (MI2984/3), RS. Porto Alegre, UFRGS, 1 vol., 2 mapas, Curso de Geologia, Instituto de Geociências.

UFRGS. Universidade Federal do Rio Grande do Sul. 2009. Mapeamento Geológico 1:25 000 de parte da Folha Passo das Canas SH-22-Y-A-III-4 (MI2984/4), RS. Porto Alegre, UFRGS, 1 vol., 2 mapas, Curso de Geologia, Instituto de 
Geociências.

UFRGS. Universidade Federal do Rio Grande do Sul. 2010. Mapeamento Geológico 1:25 000 de parte das folhas Encruzilhada SH-22-Y-A-VI-2 (MI2997/2) e Passo das Canas SH22-Y-A-III-4 (MI2984/4), RS. Porto Alegre, UFRGS, 1 vol., 2 mapas, Curso de Geologia, Instituto de Geociências.

UFRGS. Universidade Federal do Rio Grande do Sul. 2011. Mapeamento Geológico 1:25 000 de parte da folha Várzea do Capivarita SH-22-Y-B-I-4 (MI2985/2), RS. Porto Alegre, UFRGS, 1 vol., 2 mapas, Curso de Geologia, Instituto de Geociências.

Vasquez, M. L. 1997. Evolução petrogenética dos granitos da Suíte Intrusiva Encruzilhada do Sul-RS. Porto Alegre, 195p. Dissertação de Mestrado, Programa de Pós-Graduação em Geociências, Instituto de Geociências, Universidade Federal do Rio Grande do Sul.

Vernon, R.H. \& Clarke, G.L. 2008. Principles of Metamorphic Petrology. New York, Cambridge University Press, 446p.

Vernon, R.H., Clarke, G.L \& Collins, W.J. 1990. Local mid-crust granulite facies metamorphism and melting: an example in the Mount Stafford area, central Australia. In: Ashworth, J.R. \& Brown, M. (Eds.). High Temperature Metamorphism and Crustal Anatexis. London, Unwin Hyman, p. 272-319.

Vernon, R.H., Collins, W.J. \& Richards, S.W. 2003. Contrasting magmas in metapelitic and metapsammitic migmatites in

Manuscrito 529.

Editores: Rômmulo V. Conceição \& Paulo A. Souza. the Cooma Complex, Australia. Visual Geosciences, 8: 4554 .

Vielzeuf, D. \& Holloway, J.R. 1988. Experimental determination of the fluid-absent melting relations in the pelitic system. Contributions to Mineralogy and Petrology, 98: 257-276.

Waters, D.J. 1988. Partial melting and the formation of granulite facies assemblages in Namaqualand, South Africa. Journal of Metamorphic Geology, 6: 387-404.

Waters, D.J. \& Whales, C.J. 1984. Dehydratation melting and the granulite transition in metapelites from southern $\mathrm{Na}$ maqualand, South Africa. Contributions to Mineralogy and Petrology, 88: 269-275.

White, R.W., Powell, R. \& Halpin, J.A. 2004. Spatially-focused melt formation in aluminous metapelites from Broken Hill, Australia. Journal of Metamorphic Geology, 22: 825845.

Wyllie, P.J. 1977. Crustal anatexis; an experiment review. Tectonophysics, 43: 41-71.

Wyllie, P.J., Huang, W.L., Stern, C.R. \& Maaløe, S. 1976. Granitic magmas: possible and impossible sources, water contents and crystallization sequences. Canadian Journal of Earth Sciences, 13: 1007-1019.

Yardley, B.W.D. 1989. An Introduction to Metamorphic Petrology. Essex, Longman, 248 p. 
